\title{
Omega 3 fatty acids chemosensitize multidrug resistant colon cancer cells by down-regulating cholesterol synthesis and altering detergent resistant membranes composition
}

Giada Gelsomino ${ }^{1+}$, Paola A Corsetto ${ }^{2+}$, Ivana Campia', Gigliola Montorfano², Joanna Kopecka ${ }^{1}$, Barbara Castella ${ }^{3}$, Elena Gazzano ${ }^{1}$, Dario Ghigo ${ }^{1 *}$, Angela M Rizzo ${ }^{2+}$ and Chiara Riganti ${ }^{1+}$

\begin{abstract}
Background: The activity of P-glycoprotein (Pgp) and multidrug resistance related protein 1 (MRP1), two membrane transporters involved in multidrug resistance of colon cancer, is increased by high amounts of cholesterol in plasma membrane and detergent resistant membranes (DRMs). It has never been investigated whether omega 3 polyunsatured fatty acids (PUFAs), which modulate cholesterol homeostasis in dyslipidemic syndromes and have chemopreventive effects in colon cancer, may affect the response to chemotherapy in multidrug resistant (MDR) tumors.
\end{abstract}

Methods: We studied the effect of omega 3 PUFAs docosahexaenoic acid (DHA) and eicosapentaenoic acid (EPA) in human chemosensitive colon cancer HT29 cells and in their MDR counterpart, HT29-dx cells.

Results: MDR cells, which overexpressed Pgp and MRP1, had a dysregulated cholesterol metabolism, due to the lower expression of ubiquitin E3 ligase Trc8: this produced lower ubiquitination rate of 3-hydroxy-3-methylglutaryl-coenzyme A reductase (HMGCOAR), higher cholesterol synthesis, higher cholesterol content in MDR cells. We found that DHA and EPA re-activated TrC8 E3 ligase in MDR cells, restored the ubiquitination rate of HMGCoAR to levels comparable with chemosensitive cells, reduced the cholesterol synthesis and incorporation in DRMs. Omega 3 PUFAs were incorporated in whole lipids as well as in DRMs of MDR cells, and altered the lipid composition of these compartments. They reduced the amount of Pgp and MRP1 contained in DRMs, decreased the transporters activity, restored the antitumor effects of different chemotherapeutic drugs, restored a proper tumor-immune system recognition in response to chemotherapy in MDR cells.

Conclusions: Our work describes a new biochemical effect of omega 3 PUFAs, which can be useful to overcome chemoresistance in MDR colon cancer cells.

Keywords: Omega 3 polyunsaturated fatty acids, Cholesterol, Detergent resistant membranes, Multidrug resistance, ATP binding cassette transporters

\footnotetext{
*Correspondence: dario.ghigo@unito.it

${ }^{\dagger}$ Equal contributors

'Department of Oncology, University of Torino, via Santena 5/bis, 10126

Torino, Italy

Full list of author information is available at the end of the article
} 


\section{Background}

Omega 3 polyunsaturated fatty acids ( $\omega 3$ PUFAs), such as docosahexaenoic acid (DHA) and eicosapentaenoic acid (EPA), have been reported in the last years to exert significant benefits in cardiovascular diseases (where they limit the formation of atherosclerotic plaque, decrease the production of pro-inflammatory cytokines, reduce the recruitment of leukocytes to the arterial wall [1]), inflammatory diseases and cancer [2]. For instance $\omega 3$ PUFAs have been proposed as chemopreventive agents or adjuvant agents in association with radiotherapy and chemotherapy in specific tumors [3]. Despite the high number of studies reporting a significant reduction in the cardiovascular risk for patients treated with $\omega 3$ PUFA supplements, some contrasting data about the benefits of $\omega 3$ PUFAs in cardiovascular diseases have emerged recently [4-6]. Also the chemopreventive effects of $\omega 3$ PUFAs have been re-discussed in the light of recent experimental works, showing a potential positive correlation between serum levels of DHA and/or EPA and increased incidence of prostate cancer [7-10].

Worth of note colon cancer is a diet-related cancer: a diet rich of saturated fatty acids is an established risk factor for the onset of colon tumors, whereas $\omega 3$ PUFA supplementation lowers the incidence of this malignancy [11]. The chemopreventive role of $\omega 3$ PUFAs in colon cancer is supported by experimental observations showing that EPA supplementation reduces the size and number of polyps, lowers colon cell proliferation, increases apoptosis in mice harboring APC mutations [12] and in patients with a previous history of colon adenomas [13]. In vitro studies suggest that the anti-proliferative effect of $\omega 3$ PUFAs can be due to increased production of reactive oxygen species [14], increased DNA strand breaks and cell cycle arrest [15], and changes in proteins involved in apoptosis, detoxification and cell cycle control [16].

One of the most interesting metabolic effects of EPA and DHA is their positive impact on cholesterol homeostasis: in dyslipidemic rats a diet enriched with PUFAs, including $\omega 3$ PUFAs, favors the reverse cholesterol transport and increases high density lipoprotein (HDL) cholesterol [17]; in humans, $\omega 3$ FA supplementation decreases triglycerides but also increases both HDL and low density lipoprotein (LDL) cholesterol $[18,19]$. Only few works highlighted a direct effect of $\omega 3$ PUFAs on 3-hydroxy-3methylglutaryl-coenzyme A reductase (HMGCoAR), the enzyme which catalyzes the limiting step of the cholesterol biosynthesis. In rats, $\omega 3$ PUFA supplementation prevents the age-related activation of HMGCoAR in liver, by maintaining the enzyme constantly phosphorylated on serine and inhibited [20]. EPA and DHA reduce HMGCoAR activity in MCF-7 human breast cancer cells [21]. In colon cancer cells, the effects of $\omega 3$ PUFAs are more controversial: for instance, EPA inhibits HMGCoAR activity in CaCo-2 colon cancer cells [22]; DHA has little effect on the de novo synthesis of cholesterol in SW620 cells [23], although it increases the sterol regulatory element binding protein-2 (SREBP-2), which induces the transcription of several genes involved in the cholesterol synthesis - e.g. HMGCoAR and 3-hydroxy-3-methylglutaryl-coenzyme A synthase (HMGCoAS) [23,24].

We recently showed that a high rate of cholesterol synthesis in colon cancer is critical to produce the phenotype known as multidrug resistance (MDR), a condition that makes cells simultaneously unresponsive to different drugs, unrelated for chemical structure and mechanism of action $[25,26]$. One of the main mechanisms of MDR is the overexpression of membrane ATP binding cassette $(\mathrm{ABC})$ transporters, such as P-glycoprotein (Pgp/ABCB1), multidrug resistance related proteins (MRPs/ABCCs), breast cancer resistance protein (BCRP/ABCG2). By inducing the efflux of chemotherapeutic drugs, ABC transporters limit the intracellular accumulation and toxicity of several anticancer agents [27]. The activity of Pgp [28] and BCRP $[29,30]$ is directly related to the amount of cholesterol in the plasma membrane. Chemoresistant HT29-dx colon cancer cells have higher levels of HMGCoAR [25] and greater amounts of membrane cholesterol $[25,26]$ than chemosensitive HT29 cells. Drugs lowering the endogenous synthesis of cholesterol - e.g. statins and aminobisphosphonates - decrease Pgp activity [25] and expression [26] in HT29-dx colon cancer cells, increasing their chemosensitivity to Pgp substrates. A significant fraction of Pgp, MRP1 and BCRP is embedded in cholesterolrich domains of the plasma membrane, such as detergent resistant membranes (DRMs) [29-31]. Indeed, the onset of MDR in cancer is paralleled by a progressive enrichment of cholesterol in DRMs [32].

Of note, $\omega 3$ PUFAs can be incorporated in plasma membrane [33] and DRMs [34-36], where they increase the degree of lipid unsaturation, alter the physicochemical properties of these compartments (e.g. by displacing cholesterol) and impair the functional activity of several DRM-associated proteins [34,36,37]. Due to its high polyunsaturation and to its longer carbon chain, DHA is poorly compatible with the ordered cholesterol/glycosphingolipids disposition in DRMs, and it is a stronger DRM-disrupting agent than EPA [34].

To our knowledge, there is no information on the effects exerted by $\omega 3$ PUFAs on cholesterol metabolism, DRMs composition, activity of $\mathrm{ABC}$ transporters and MDR phenotype in colon cancer.

In this work we investigated: 1) whether and how $\omega 3$ PUFAs modulate the synthesis of cholesterol and the composition of DRMs in human chemosensitive and chemoresistant colon cancer cells; 2) whether they impair the activity of $\mathrm{ABC}$ transporters, inducing chemosensitization. To this aim we treated human chemosensitive colon cancer HT29 cells and their resistant counterpart (HT29-dx 
cells) with EPA and DHA; to verify the specificity of $\omega 3$ PUFA effects, we compared the effects of EPA and DHA with those of the omega 6 polyunsaturated fatty acid ( $\omega 6$ PUFA) arachidonic acid (AA).

\section{Results}

w3PUFAs reduce the de novo cholesterol synthesis in colon cancer cells

Chemoresistant HT29-dx colon cancer cells exhibited a significantly higher synthesis of cholesterol when compared to chemosensitive HT29 cells (Figure 1A). The $\omega 6$ PUFA AA did not affect the cholesterol synthesis in both cell lines, except at $200 \mu \mathrm{M}$ AA; $\omega 3$ PUFAs DHA and EPA decreased the cholesterol synthesis starting from $50 \mu \mathrm{M}$. Such decrease was more pronounced and statistically significant in HT29-dx cells (Figure 1A).

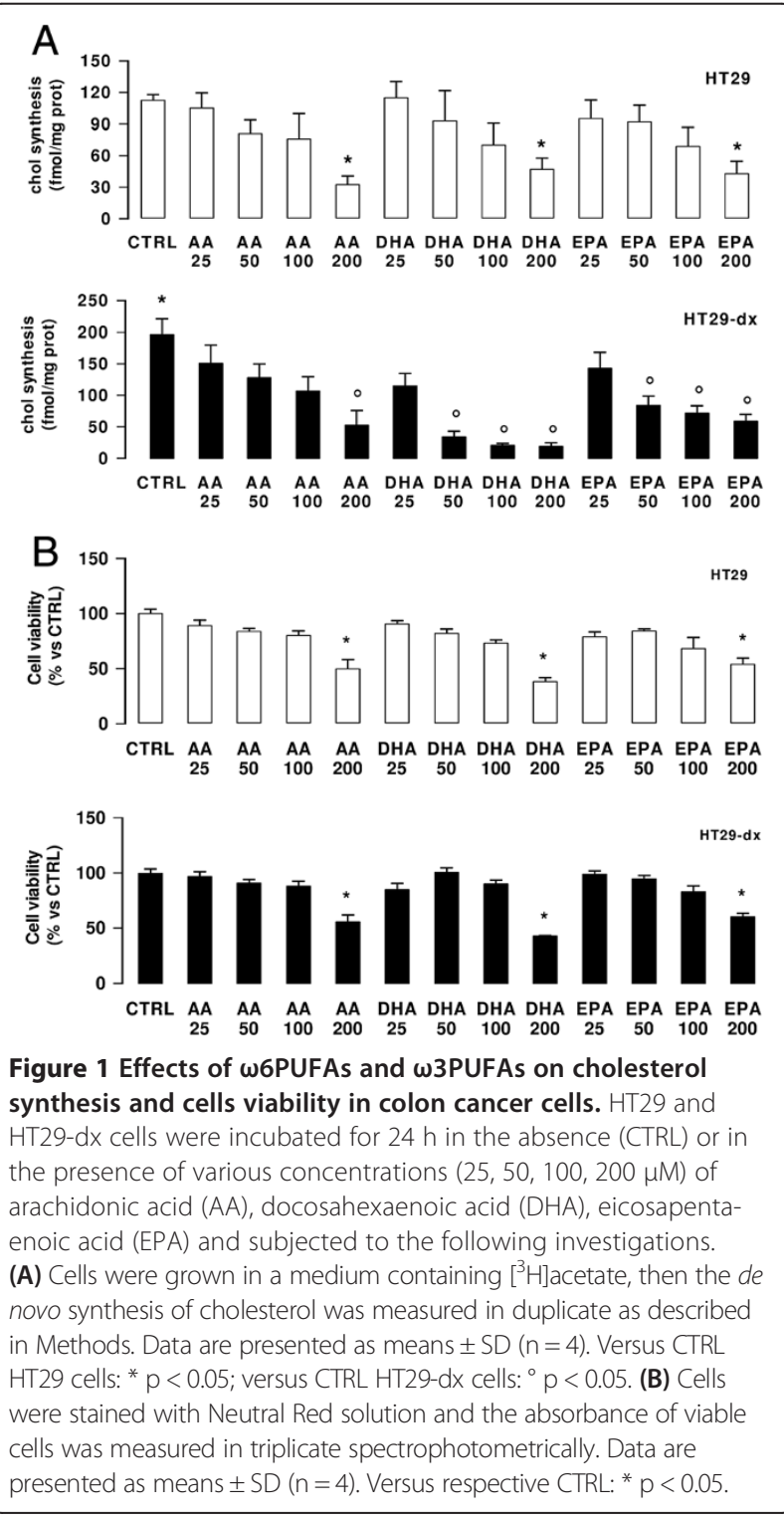

All PUFAs reduced the viability of both cell lines at $200 \mu \mathrm{M}$ (Figure 1B); at $50 \mu \mathrm{M}$ they did not impair cell viability (Figure 1B), did not induce apoptosis (Additional file 1A) and necrotic/immunogenic death (Additional file 1B).

Since $50 \mu \mathrm{M}$ PUFA was the lowest concentration able to decrease the endogenous synthesis of cholesterol in chemoresistant cells without exerting toxicity per se, it was chosen for all the subsequent experiments.

\section{w3PUFAs reduce HMGCoAR expression in colon}

chemoresistant cancer cells by increasing its ubiquitination

The higher synthesis of cholesterol in HT29-dx cells was accompanied by higher enzymatic activity (Figure 2A) and protein expression (Figure $2 \mathrm{~B}$ ) of HMGCoAR, compared to HT29 cells. Whereas AA did not modify these parameters, DHA and EPA significantly lowered the activity (Figure 2A) and expression (Figure 2B) of HMGCoAR in chemoresistant cells. Interestingly, they had no effect in chemosensitive cells.

HT29-dx cells had higher levels of HMGCoAR (Figure 3A) and HMGCoAS (Additional file 2A) mRNA than HT29 cells, and higher nuclear levels of the transcription factor SREBP-2 (Additional file 2B). Neither $\omega 6$ PUFA nor $\omega 3$ PUFAs changed the levels of HMGCoAR (Figure 3A) and HMGCoAS (Additional file 2A) mRNA, and the amount of nuclear SREBP-2 (Additional file 2B). These results suggest that DHA and EPA did not decrease HMGCoAR expression by down-regulating gene transcription. SREBP-1 was unmodified in each experimental condition and did not differ between HT29 and HT29-dx cells (Additional file 2B).

Since HMGCoAR can be negatively regulated at posttranscriptional level, by phosphorylation on serine [38] or ubiquitination followed by proteasome degradation [39], we next investigated whether $\omega 3$ PUFAs may affect these events. HMGCoAR was basally phosphorylated on serine in both HT29 and HT29-dx cells without appreciable differences between the two cell populations; PUFAs did not modify the phosphorylation status (Figure 3B, left panel).

In HT29 cells HMGCoAR was highly ubiquitinated, both in the absence or presence of PUFAs. By contrast, the ubiquitination of HMGCoAR was lower in HT29-dx cells; DHA and EPA, but not AA, restored the ubiquitination of HMGCoAR to the same level observed in HT29 cells (Figure 3B, left panel). The proteasome inhibitor MG-132 further increased the amount of ubiquitinated HMGCoAR, in both HT29 and HT29-dx cells, cultured in the absence or presence of DHA (Figure 3B, right panel). These data suggest that the ubiquitination of HMGCoAR was followed by its degradation via the proteasome system.

The endoplasmic reticulum (ER) proteins Insig-1 and Insig- 2 are known to mediate the sterol-dependent degradation of HMGCoAR, by recruiting at least two ER- 


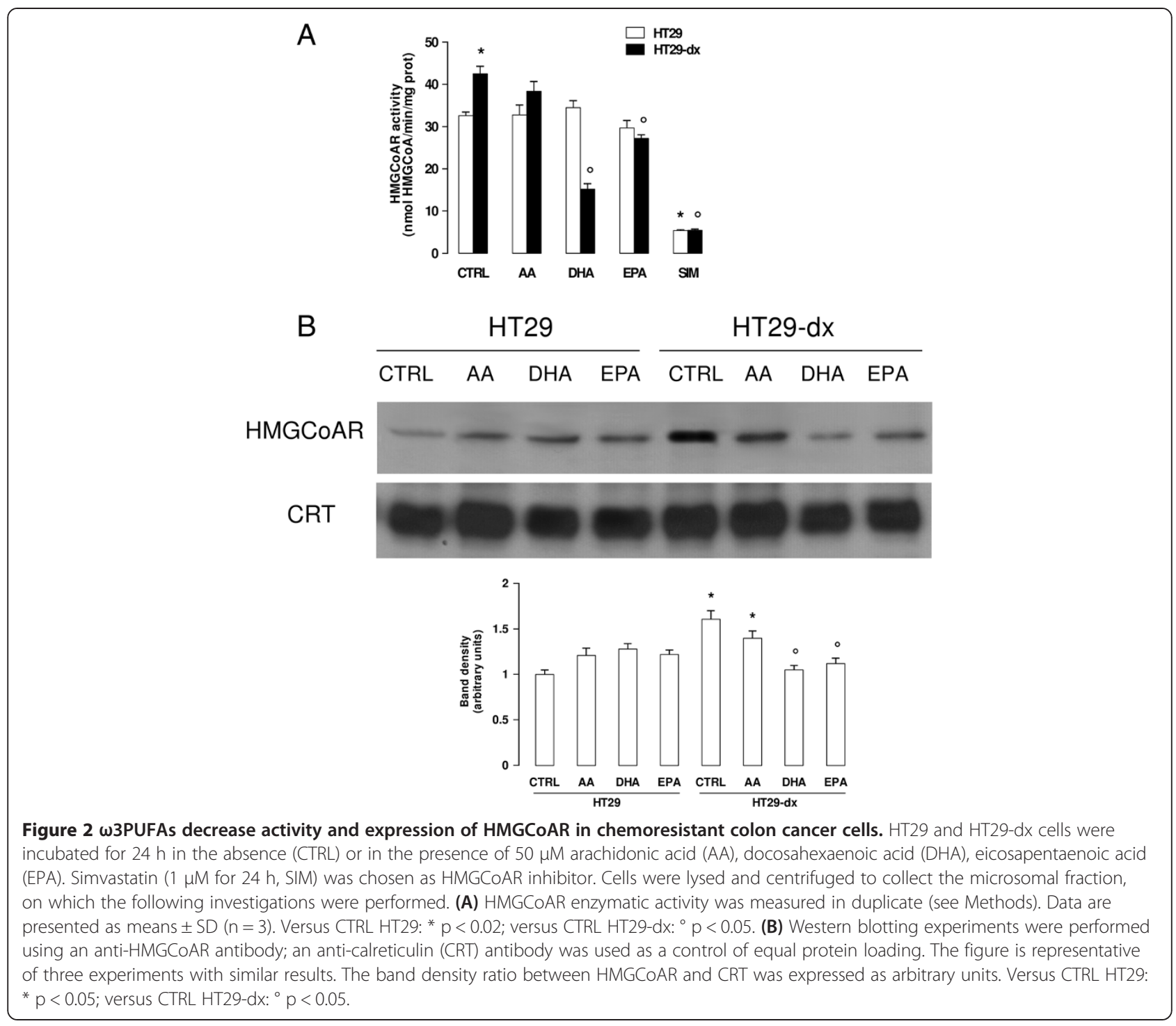

associated E3 ligases, namely gp78 and Trc8 [39]. gp78 cooperates with the E2 ubiquitin-conjugating enzyme Ube2g2 to ubiquitinate HMGCoAR [40]. All these proteins are components of the so-called ER-associated degradation (ERAD) system, and we investigated whether they are modulated by $\omega 3$ PUFAs. To measure the activity of the ERAD system in cell extracts, microsomal fractions from HT29 and HT29-dx cells were incubated with an E1 ubiquitin-activating enzyme, Ube2g2 enzyme, ATP and ubiquitin. Then HMGCoAR was isolated by immunoprecipitation and the ubiquitin bound to HMGCoAR was quantified. As shown in Figure 4A, HT29-dx cells exhibited a lower ubiquitination of HMGCoAR, in comparison to HT29 cells. The ubiquitination was not affected by AA. DHA and EPA instead increased the amount of ubiquitinated HMGCoAR in HT29-dx cells to levels comparable to those observed in HT29 cells.
We did not find any difference in the expression of Insig-1, Insig-2 and gp78 between chemosensitive and chemoresistant cells, either untreated or treated with AA, DHA and EPA (Figure 4B). By contrast, Trc8 expression was lower in HT29-dx cells, providing a putative explanation for the lower ubiquitination of HMGCoAR in these cells. Since in HT29-dx cells DHA and EPA did not modify the expression of Trc8 (Figure 4B), but increased the ubiquitination of HMGCoAR versus the control (Figures $3 \mathrm{~B}$ and $4 \mathrm{~A}$ ), we next investigated whether these PUFAs directly activate $\operatorname{Trc} 8$ enzyme. In a cell-free system, containing purified HMGCoAR, recombinant $\operatorname{Trc} 8$ and the necessary components of the ubiquitination machinery, DHA and EPA dosedependently increased the ubiquitination of HMGCoAR, whereas AA was devoid of effects (Figure 4C). On the other hand, DHA and EPA did not increase the ubiquitination when gp78 replaced $\operatorname{Trc} 8$ as E3 ligase 


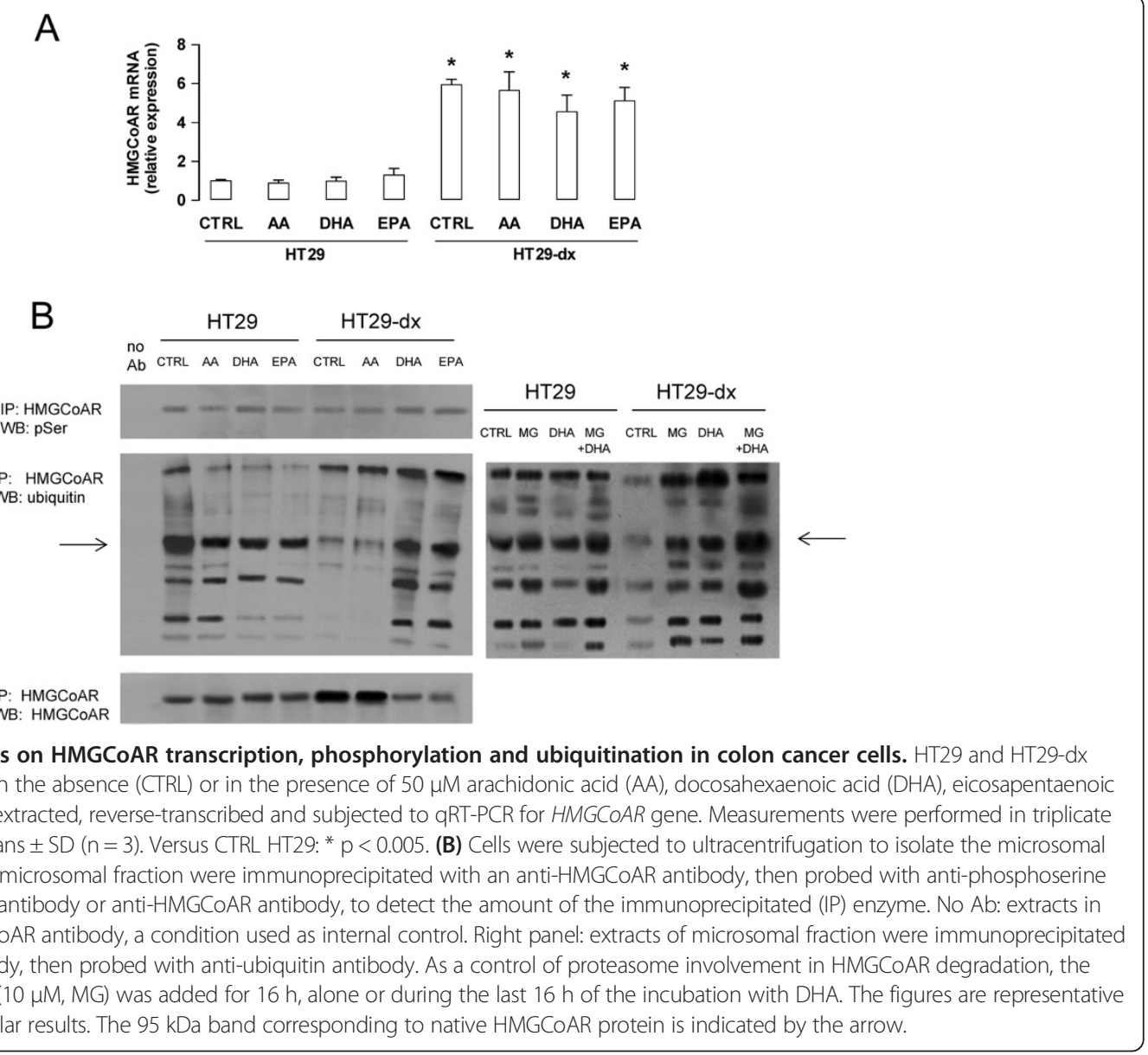

(Figure 4C), suggesting that they are specific activators of $\operatorname{Trc} 8$.

\section{W3PUFAs alter the DRMs composition and reduce the DRM-associated Pgp and MRP1 in chemoresistant colon cancer cells}

Consistently with the higher rate of cholesterol synthesis (Figure 1A), HT29-dx cells had twice more cholesterol in whole cell than HT29 cells (Figure 5A). DHA and EPA decreased cholesterol levels only in HT29-dx cells (Figure 5A). As expected, DRMs were characterized by a high cholesterol content in both cell lines (Figure 5B); again, only in HT29-dx cells DHA and EPA were able to significantly decrease cholesterol (Figure $5 \mathrm{~B}$ ).

PUFAs were incorporated both in whole cell lipids (Tables 1 and 2) and DRMs (Tables 3 and 4). Compared to the other PUFAs, EPA was integrated with higher efficiency in whole cell lipids in HT29 cells (11.21-fold increase) and further metabolized to docosapentaenoic acid (DPA); it was incorporated with a bit lower efficiency in HT29-dx cells (7.03-fold increase) without any further metabolism (Tables 1 and 2). DHA showed the same integration efficiency in both cell lines (6.63-fold increase in HT29 cells and 5.86-fold increase in HT29-dx cells). w3PUFAs significantly reduced the AA whole content in both cell lines.

Both DHA and EPA were integrated in DRM phospholipids even if with lower efficiency compared to their incorporation in whole cell lipids (Tables 3 and 4); in particular in HT29-dx cells they were respectively $4.50 \pm$ $1.29 \%$ and $3.50 \pm 1.20 \%$ of total fatty acids (Table 4 ).

HT29-dx cells had higher amounts of Pgp and MRP1 on their surface (Figure 5C and Table 5). Interestingly, the decrease in cell membrane cholesterol elicited by DHA and EPA was accompanied by diminished surface levels of Pgp and MRP1, which became similar to the levels detected in HT29 cells (Figure 5C and Table 5). In particular, Pgp and MRP1 were more expressed in DRMs of HT29-dx cells (Figure 5D) and their DRM-association was significantly reduced by $\omega 3$ PUFAs (Figure $5 \mathrm{D}$ ). AA, which was incorporated in whole cell lipids (Tables 1 and 2) and DRMs (Tables 3 and 4), without changing the amount of cholesterol (Figure 5A-B), did not modify Pgp and MRP1 levels (Figure 5C-D; Table 5).

The surface level of BCRP was similar in HT29 and HT29-dx cells (Figure 5C and Table 5), but the DRMassociated BCRP was slightly higher in HT29-dx cells 


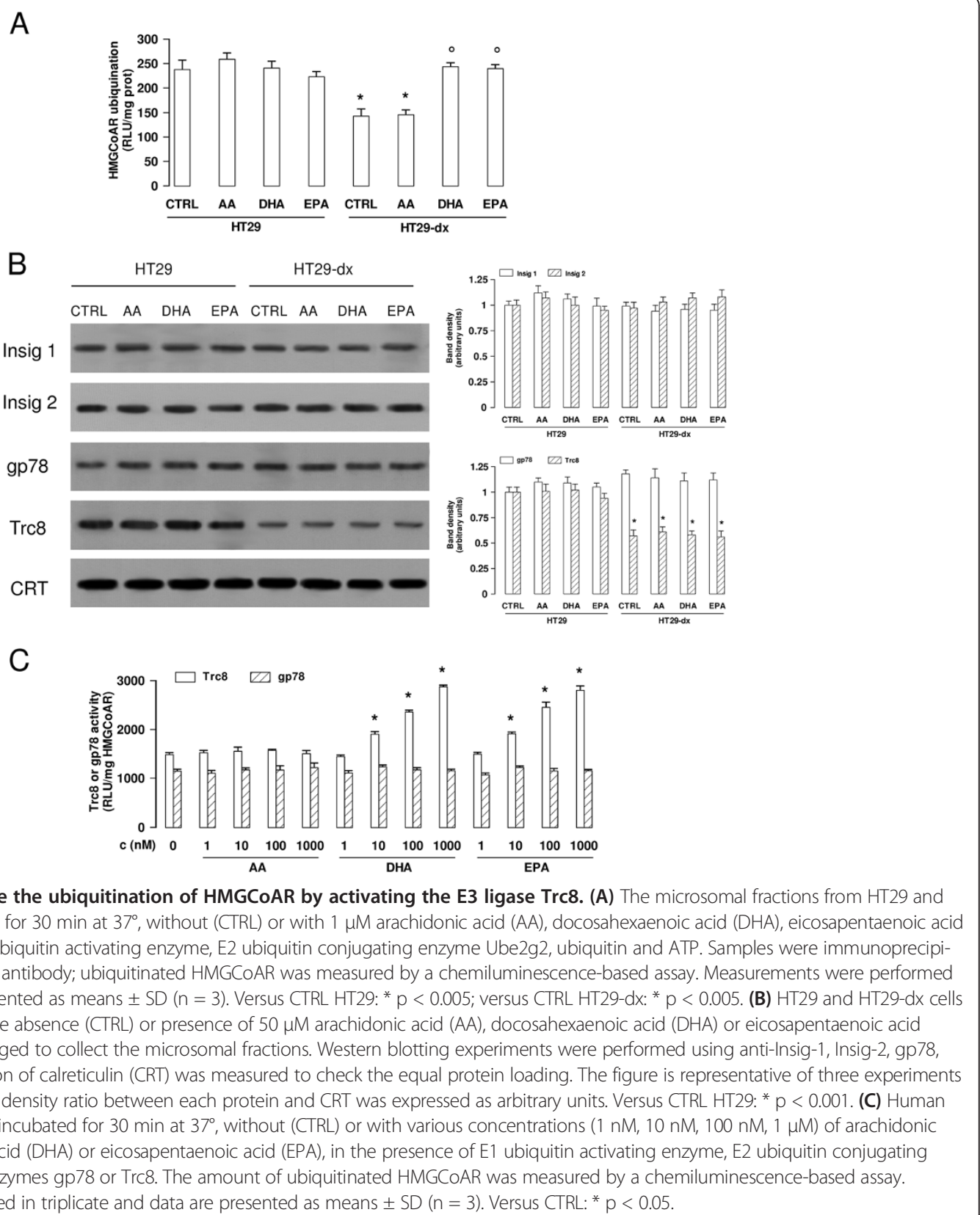

(Figure 5D). According to the densitometric analysis, DHA and - at lesser extent - AA and EPA increased the amount of DRM-associated BCRP in both HT29 and HT29-dx cells (Figure 5D). The changes of ABC transporters on cell surface were not due to differences in the absolute amount of Pgp, MRP1 and BCRP: all these proteins were higher in the whole cell lysate of HT29-dx cells compared to HT29 cells and were not affected by AA, DHA or EPA (Additional file 3). These results suggest that the changes of Pgp and MRP1 surface levels are likely due to the redistribution between plasma membrane and cytosol.
W3PUFAs sensitize multidrug-resistant colon cancer cells to the antitumor effects of Pgp and MRP1 substrates

The anthracycline doxorubicin, used to generate the resistant HT29-dx cell population [41], is a substrate of both Pgp and MRP1 [27]. Although anthracyclines are not used in colon cancer therapy, we chose doxorubicin as a reliable tool to clarify whether $\omega 3$ PUFAs chemosensitize resistant cells to anticancer drugs effluxed by Pgp and MRP1. Doxorubicin was indeed less accumulated in HT29-dx cells (Figure 6A) and did not reduce their viability (Figure 6B). In correlation with the reduction of Pgp and MRP1 at cell surface, DHA and EPA increased 
A

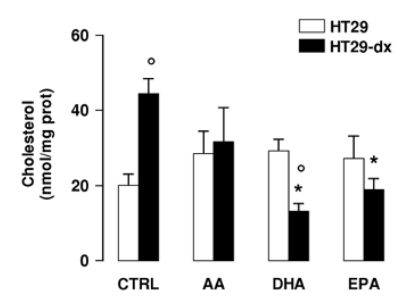

C

Pgp

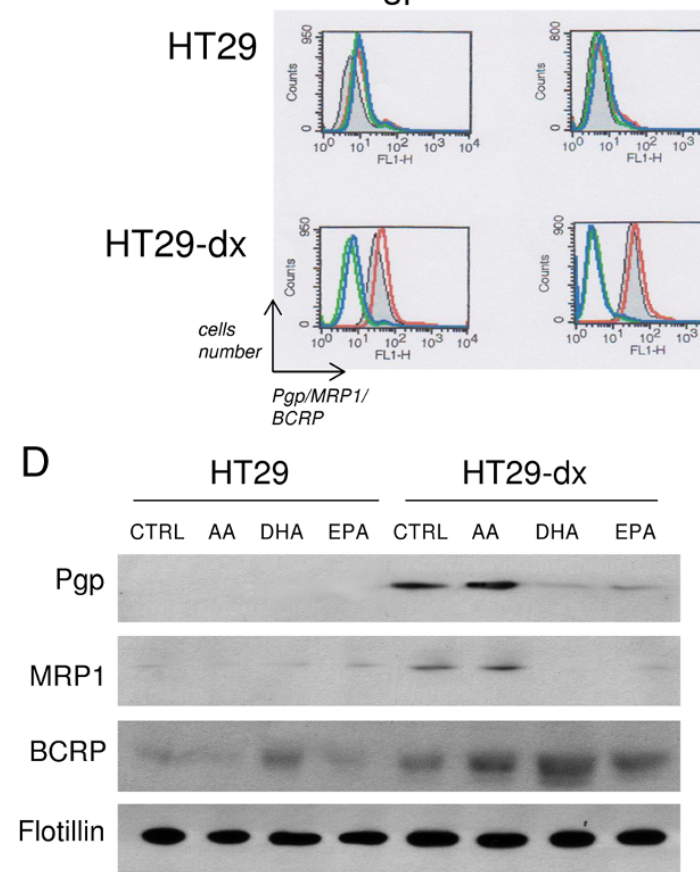

HT29-dx
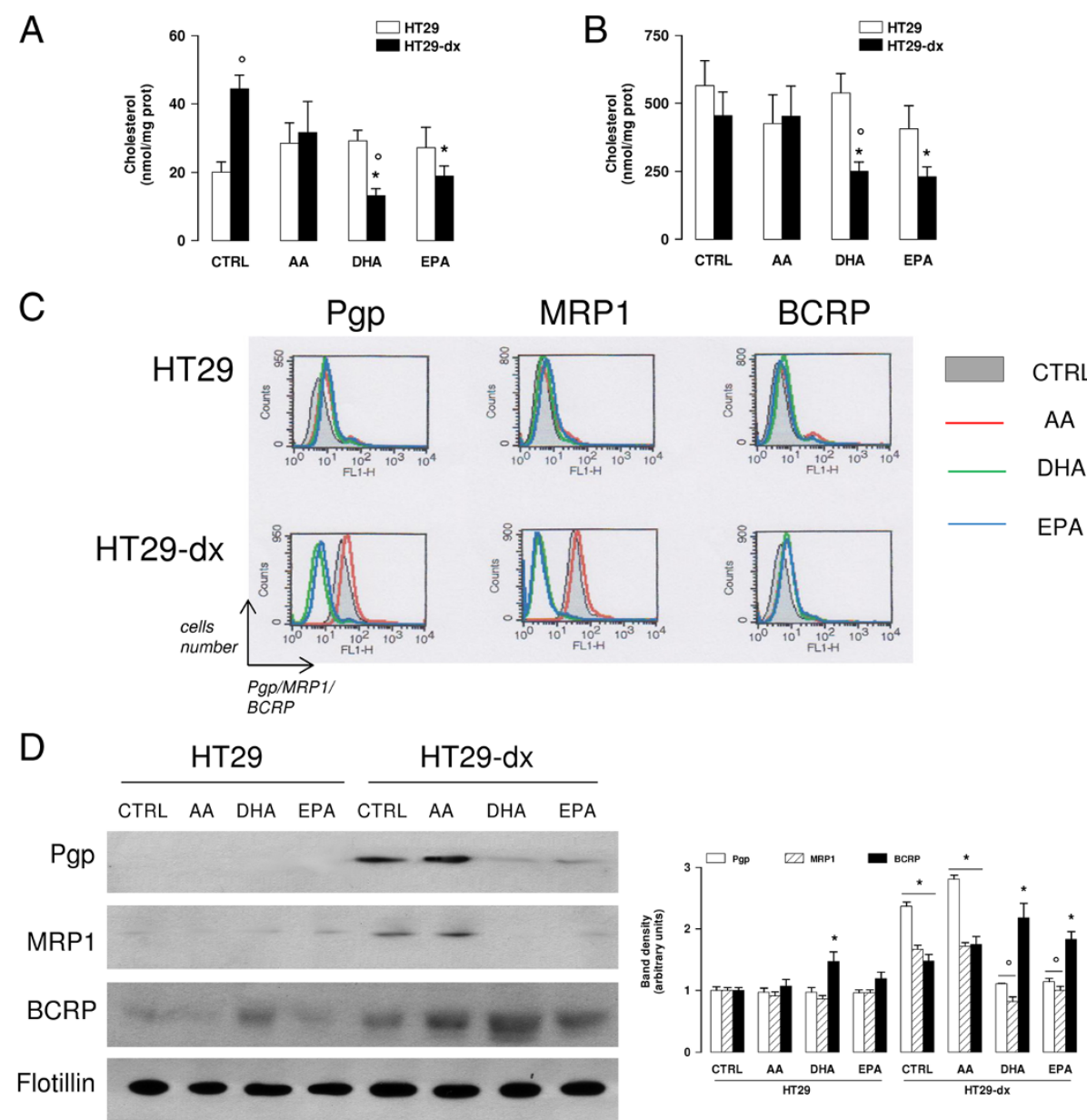

Figure 5 Effects of w3PUFAs on cholesterol and ABC transporters in whole cell and DRMs. HT29 and HT29-dx cells were incubated for $48 \mathrm{~h}$ in the absence (CTRL) or in the presence of $50 \mu \mathrm{M}$ arachidonic acid (AA), docosahexaenoic acid (DHA), eicosapentaenoic acid (EPA). (A) Total lipids were extracted and the amount of cholesterol was measured in triplicate as reported under Methods. Data are presented as mean \pm SD $(n=3)$. Versus respective CTRL: * $p<0.01 ; H T 29-d x$ versus HT29 cells: ${ }^{\circ} p<0.01$. (B) DRMs were isolated as detergent-resistant membranes by separation on sucrose gradient; then the amount of cholesterol was measured as reported in Methods. Data are presented as mean \pm SD $(n=4)$. Versus respective CTRL: * $p<0.05$; HT29-dx versus HT29 cells: ${ }^{\circ} p<0.01$. (C) Surface levels of Pgp, MRP1 and BCRP were measured in non-permeabilized cells by flow cytometry. The figures shown here are representative of three similar experiments, performed in triplicate. (D) Western blot detection of Pgp, MRP1 and BCRP on DRM extracts. Flotillin expression was used as control of equal protein loading. The figure is representative of two experiments with similar results. The band density ratio between each protein and flotillin was expressed as arbitrary units. Versus CTRL HT29: * $p<0.05$; versus CTRL HT29-dx: $p<0.005$.

the intracellular doxorubicin retention (Figure 6A) and restored its cytotoxicity in HT29-dx cells (Figure 6B). Anthracyclines are amongst the few anticancer drugs able to kill cancer cells by exerting direct cytotoxicity on tumor cell and by inducing an immunogenic cell death. This type of cell death is characterized by the extracellular release of ATP and HMGB1, by the surface translocation of calreticulin, and by the subsequent phagocytosis of tumor cells by dendritic cells (DCs) $[42,43]$. While doxorubicin elicited all these events in HT29 cells, it was ineffective in HT29-dx cells (Additional file 4A-B; Figure 6C-D; Table 6). EPA and DHA, which did not further enhance the effects of doxorubicin in chemosensitive cells, restored the doxorubicin- mediated release of extracellular ATP (Additional file 4A) and HMGB1 (Additional file 4B), the translocation of calreticulin on cell surface (Figure 6C; Table 6) and the DC-mediated phagocytosis of HT29-dx cells (Figure 6D), confirming that they fully restored the proimmunogenic effects of doxorubicin. Of note, neither DHA nor EPA alone increased ATP and HMGB1 release, calreticulin translocation and cells phagocytosis (Additional file 4A-B; Figure 6C-D; Table 6), suggesting that they were not immune-activating agents per $s e$, but only enhancers of doxorubicin activity. Again, AA was completely ineffective in restoring doxorubicin cytotoxicity and pro-immunogenic effects in HT29-dx cells (Additional file 4; Figure 6; Table 6). 
Table 1 Fatty acids composition of whole HT29 cells

\begin{tabular}{|c|c|c|c|c|}
\hline & CTRL & AA & DHA & EPA \\
\hline C16:0 & $30.131 \pm 2.328$ & $28.882 \pm 2.166$ & $30.803 \pm 2.728$ & $29.952 \pm 3.450$ \\
\hline C16:1 & $10.990 \pm 1.086$ & $8.669 \pm 0.877$ & $9.091 \pm 1.042$ & $7.308 \pm 1.693$ \\
\hline C18:0 & $13.155 \pm 0.842$ & $12.327 \pm 0.595$ & $12.052 \pm 1.093$ & $13.176 \pm 1.604$ \\
\hline C18:1 & $29.677 \pm 1.260$ & $30.412 \pm 1.259$ & $29.317 \pm 2.910$ & $26.824 \pm 2.418$ \\
\hline C18:2 & $4.003 \pm 0.547$ & $2.753 \pm 0.221$ & $2.612 \pm 0.322$ & $2.681 \pm 0.317$ \\
\hline C18:3 $\omega-3$ & $0.513 \pm 0.143$ & $1.125 \pm 0.202^{*}$ & $0.565 \pm 0.073$ & $0.723 \pm 0.112$ \\
\hline C18:3 $\omega-6$ & $0.416 \pm 0.060$ & $0.129 \pm 0.020^{*}$ & $0.176 \pm 0.038^{*}$ & $0.131 \pm 0.240$ \\
\hline C20:3 & $1.222 \pm 0.176$ & $0.814 \pm 0.035$ & $0.833 \pm 0.060$ & $0.791 \pm 0.031$ \\
\hline C20:4 (AA) & $6.032 \pm 1.164$ & $11.394 \pm 1.177^{* *}$ & $3.687 \pm 0.332^{*}$ & $3.594 \pm 0.344^{*}$ \\
\hline C20:5 (EPA) & $1.536 \pm 0.337$ & $1.071 \pm 0.220$ & $1.638 \pm 0.097$ & $11.570 \pm 2.685^{* *}$ \\
\hline C22:5 & $0.743 \pm 0.126$ & $0.706 \pm 0.123$ & $0.886 \pm 0.101$ & $1.561 \pm 0.306^{* *}$ \\
\hline C22:6 (DHA) & $1.760 \pm 0.380$ & $1.716 \pm 0.350$ & $8.339 \pm 2.375^{* *}$ & $1.689 \pm 0.300$ \\
\hline $\mathrm{SFA}^{\mathrm{a}}$ & $43.285 \pm 2.860$ & $41.209 \pm 2.345$ & $42.855 \pm 3.196$ & $43.128 \pm 4.836$ \\
\hline MUFA $^{\text {b }}$ & $40.667 \pm 1.579$ & $39.081 \pm 1.561$ & $38.409 \pm 3.640$ & $34.132 \pm 3.632$ \\
\hline$\omega-6$ & $8.990 \pm 0.759$ & $15.091 \pm 1.196^{* *}$ & $7.308 \pm 0.629$ & $7.197 \pm 0.608$ \\
\hline$\omega-3$ & $4.553 \pm 0.738$ & $4.620 \pm 0.643$ & $11.429 \pm 2.477^{* *}$ & $15.543 \pm 3.073^{* *}$ \\
\hline$\omega-6 / \omega-3$ & $2.386 \pm 0.307$ & $3.371 \pm 0.295$ & $0.748 \pm 0.172^{* *}$ & $0.513 \pm 0.095^{* *}$ \\
\hline Fold increase ${ }^{c}$ & & 3.008 & 6.634 & 11.209 \\
\hline
\end{tabular}

The rescue of chemosensitivity was not limited to doxorubicin: indeed, the IC50 of irinotecan, another substrate of Pgp [44], was higher in HT29-dx cells than in HT29 cells (Figure 7A). The drug effectively reduced the proliferation of HT29 cells, not of HT29-dx cells (Figure 7B). DHA and EPA lowered the IC50 of irinotecan in HT29-dx cells to a value similar to HT29 cells (Figure 7A). Moreover, they restored the antiproliferative effect of irinotecan in drug-resistant cells (Figure 7B).

\section{Discussion}

In this work we investigated whether w3PUFAs - DHA and EPA - chemosensitize MDR colon cancer cells, by modulating the endogenous synthesis of cholesterol and the cholesterol amount in plasma membrane, two factors that affect $\mathrm{ABC}$ transporters activity and determine a MDR phenotype $[25,26,28,30]$.

PUFAs have been reported to induce apoptosis in HT29 cells at concentrations higher than $200 \mu \mathrm{M}$ after $24 \mathrm{~h}$ [15]. They are cytotoxic in colon cancer cells at $50 \mu \mathrm{M}$ for prolonged periods (e.g. 6 days) [45], but do not reduce cell survival after $72 \mathrm{~h}$ [46]. Since we used $\omega 3$ PUFAs and $\omega 6$ PUFA at $50 \mu \mathrm{M}$ for $24 \mathrm{~h}$, it is likely that we did not detect any toxicity because of the short incubation time. Interestingly, chemosensitive and chemoresistant cells displayed equal sensitivity to the toxic effects of the highest concentrations of PUFAs, suggesting that the MDR phenotype is not important for the PUFAs' cytotoxicity. The similar toxicity profile observed in HT29 and HT29-dx cells might also suggest that PUFAs are not effluxed by the ABC transporters present in HT29-dx cells.

Within cells, protein-bound fatty acids may reach concentrations up to $100 \mu \mathrm{M}[15,47]$. In order to work at a non-toxic and physiological-like concentration of PUFAs, we used $\omega 3$ PUFAs and $\omega 6$ PUFA at $50 \mu \mathrm{M}$ in all the functional assays.

AA significantly reduced the de novo synthesis of cholesterol only at a cytotoxic concentration $(200 \mu \mathrm{M})$, suggesting that such decrease was a non-specific effect. $50 \mu \mathrm{M}$ DHA and EPA did not reduce the cholesterol synthesis in chemosensitive HT29 cells, but significantly decreased it in chemoresistant HT29-dx cells. Since the basal rate of cholesterol synthesis was higher in HT29-dx cells than in HT29 cells, it is not surprising that the effect of cholesterol-lowering agents - such as DHA and EPA was more evident in MDR cells. On the other hand, the different effects exerted by $\omega 3$ PUFAs in chemosensitive and chemoresistant cells may be indicative of different regulation mechanisms in cholesterol synthesis. HT29-dx cells had higher activity and expression of HMGCoAR mRNA and protein, accompanied by higher nuclear levels of the transcriptional activator SREBP-2. SREBP-2 is upregulated by intracellular sterols and by the transcription factor hypoxia inducible factor- $1 \alpha$ (HIF-1 $\alpha$ ) [48], which is 
Table 2 Fatty acids composition of whole HT29-dx cells

\begin{tabular}{|c|c|c|c|c|}
\hline & CTRL & AA & DHA & EPA \\
\hline C16:0 & $28.821 \pm 2.333$ & $28.352 \pm 2.367$ & $30.020 \pm 3.349$ & $29.630 \pm 2.872$ \\
\hline C16:1 & $10.532 \pm 0.945$ & $9.955 \pm 1.003$ & $9.027 \pm 0.986$ & $9.652 \pm 0.905$ \\
\hline C18:0 & $12.386 \pm 1.082$ & $11.401 \pm 1.731$ & $12.870 \pm 2.455$ & $12.229 \pm 1.465$ \\
\hline C18:1 & $30.878 \pm 1.510$ & $31.793 \pm 2.214$ & $30.288 \pm 3.019$ & $31.674 \pm 2.552$ \\
\hline C18:2 & $4.266 \pm 0.792$ & $2.563 \pm 0.239$ & $2.182 \pm 0.368$ & $3.025 \pm 0.184$ \\
\hline C18:3 $\omega-3$ & $0.438 \pm 0.068$ & $0.955 \pm 0.165^{* *}$ & $0.514 \pm 0.094$ & $0.659 \pm 0.036^{*}$ \\
\hline C18:3 $\omega-6$ & $0.113 \pm 0.011 \S$ & $0.111 \pm 0.013$ & $0.147 \pm 0.038$ & $0.107 \pm 0.009$ \\
\hline$C 20: 3$ & $1.181 \pm 0.209$ & $0.828 \pm 0.027$ & $0.874 \pm 0.107$ & $0.895 \pm 0.080$ \\
\hline C20:4 (AA) & $6.571 \pm 1.563$ & $9.813 \pm 0.560^{*}$ & $3.182 \pm 0.590^{*}$ & $3.694 \pm 0.431^{*}$ \\
\hline C20:5 (EPA) & $1.707 \pm 0.425$ & $0.812 \pm 0.060$ & $1.477 \pm 0.227$ & $5.852 \pm 0.677^{* *}$ \\
\hline C22:5 & $0.875 \pm 0.080$ & $0.823 \pm 0.102$ & $0.835 \pm 0.166$ & $1.101 \pm 0.106$ \\
\hline C22:6 (DHA) & $2.280 \pm 0.467$ & $1.594 \pm 0.274$ & $8.345 \pm 2.915^{*}$ & $1.481 \pm 0.350$ \\
\hline $\mathrm{SFA}^{\mathrm{a}}$ & $41.208 \pm 2.757$ & $40.753 \pm 3.507$ & $42.890 \pm 5.505$ & $41.860 \pm 4.067$ \\
\hline MUFA $^{\mathrm{b}}$ & $41.410 \pm 2.336$ & $41.748 \pm 3.196$ & $39.555 \pm 3.886$ & $41.326 \pm 3.443$ \\
\hline$\omega-6$ & $12.083 \pm 2.310$ & $13.315 \pm 0.539$ & $6.385 \pm 0.735^{*}$ & $7.721 \pm 0.309^{*}$ \\
\hline$\omega-3$ & $5.300 \pm 0.904$ & $4.184 \pm 0.315$ & $11.171 \pm 2.988^{*}$ & $9.094 \pm 0.697^{* *}$ \\
\hline$\omega-6 / \omega-3$ & $2.271 \pm 0.198$ & $3.208 \pm 0.129^{* *}$ & $0.679 \pm 0.162^{* *}$ & $0.863 \pm 0.070^{* * \S}$ \\
\hline Fold increase ${ }^{c}$ & & 2.782 & 5.862 & 7.028 \\
\hline
\end{tabular}

constitutively active in HT29-dx cells also under normoxic conditions, but undetectable in HT29 cells [26]. The increased activation of HIF-1 $\alpha /$ SREBP-2 axis may explain why HT29-dx cells have higher levels of HMGCoAR and HMGCoAS mRNA, despite the higher levels of cholesterol $[25,26]$. It is unlikely however that $\omega 3$ PUFAs interfere with this axis in HT29-dx cells: they indeed reduced HMGCoAR activity and protein in chemoresistant cells, but did not decrease the nuclear translocation of SREBP-2 and the transcription of $H M G C O A R$ gene. Our data are partially in contrast with previous works showing that DHA activated SREBP-2 in SW620 colon cancer cells [23,24], without changing however the transcription of HMGCoAR [23]. As far as we know, these works were performed on colon cancer cells without a MDR phenotype; this may explain the different behavior of DHA in SW620 cells and in chemoresistant HT29-dx cells. Also in our hands DHA and EPA did not produce any changes in chemosensitive HT29 cells, which maintained lower HMGCoAR activity and expression, and lower nuclear SREBP-2 compared with HT29-dx cells.

Since DHA and EPA only reduced the amount of HMGCoAR protein, without changing the HMGCoAR mRNA or the enzyme phosphorylation, we next wondered whether $\omega 3$ PUFAs modulated HMGCoAR degradation via the ubiquitin/proteasome system. Interestingly,
MDR cells showed a lower level of enzyme ubiquitination than chemosensitive cells, a situation that may explain the increased basal amount of HMGCoAR protein. In both cell lines, the proteasome inhibitor MG-132 further increased the amount of ubiquitinated HMGCoAR, suggesting that the ubiquitination was followed by proteasomal degradation. Of note, whereas AA did not affect the rate of ubiquitination, DHA and EPA increased the ubiquitination of HMGCoAR in HT29-dx cells but not in HT29 cells.

When we analyzed the ubiquitination of HMGCoAR in microsomal fraction, we found that the activity of the ERAD system was significantly lower in MDR cells; DHA and EPA increased ERAD activity to the same levels of HT29 cells. In order to investigate the putative target of $\omega 3$ PUFAs, we first analyzed the expression of Insig- 1 and -2, which cooperate with the ER-associated ubiquitin E3 ligases gp78 and Trc8 in the degradation of HMGCoAR [39]. We did not detect any difference between HT29 and HT29-dx cells, in the absence or presence of AA, DHA and EPA, except for Trc8. This E3 ligase was more expressed in HT29 cells than in HT29-dx cells: such difference may explain the differential expression and degradation of HMGCoAR between chemosensitive and chemoresistant cells. Since neither DHA nor EPA changed the expression of $\operatorname{Trc} 8$ and gp78, but they both increased the ubiquitination of HMGCoAR, we hypothesized that 
Table 3 Detergent resistant membrane (DRM) fatty acids composition of HT29 cells

\begin{tabular}{|c|c|c|c|c|}
\hline & CTRL & AA & DHA & EPA \\
\hline C16:0 & $35.973 \pm 2.332$ & $31.712 \pm 1.344$ & $31.684 \pm 1.527$ & $31.238 \pm 2.09$ \\
\hline C16:1 & $6.470 \pm 1.522$ & $8.098 \pm 0.457$ & $6.761 \pm 1.409$ & $9.479 \pm 0.789$ \\
\hline C18:0 & $14.923 \pm 0.789$ & $15.291 \pm 0.352$ & $16.787 \pm 1.179$ & $14.685 \pm 0.971$ \\
\hline C18:1 & $32.203 \pm 1.068$ & $30.241 \pm 2.900$ & $32.918 \pm 2.472$ & $30.065 \pm 2.061$ \\
\hline C18:2 & $3.184 \pm 0.283$ & $3.252 \pm 0.895$ & $2.871 \pm 0.281$ & $4.048 \pm 1.115$ \\
\hline C18:3 $\omega-3$ & $0.352 \pm 0.035$ & $0.610 \pm 0.150$ & $0.389 \pm 0.015$ & $0.322 \pm 0.084$ \\
\hline$C 18: 3 \omega-6$ & $0.521 \pm 0.154$ & $0.326 \pm 0.059$ & $0.389 \pm 0.138$ & $2.567 \pm 1.893$ \\
\hline C20:3 & $0.835 \pm 0.160$ & $0.308 \pm 0.018$ & $0.690 \pm 0.022$ & $0.581 \pm 0.085$ \\
\hline C20:4 (AA) & $3.183 \pm 0.477$ & $8.455 \pm 1.782^{* * *}$ & $3.303 \pm 0.159$ & $3.466 \pm 0.428$ \\
\hline C20:5 (EPA) & $0.888 \pm 0.178$ & $0.589 \pm 0.036$ & $1.260 \pm 0.353$ & $1.827 \pm 0.304^{*}$ \\
\hline C22:5 & $0.394 \pm 0.066$ & $0.590 \pm 0.133$ & $0.388 \pm 0.101$ & $0.565 \pm 0.117$ \\
\hline C22:6 (DHA) & $1.077 \pm 0.157$ & $1.069 \pm 0.082$ & $2.553 \pm 0.494^{* *}$ & $1.158 \pm 0.178$ \\
\hline$S F A^{a}$ & $50.895 \pm 2.810$ & $47.003 \pm 1.387$ & $48.471 \pm 1.743$ & $45.923 \pm 2.935$ \\
\hline MUFA $^{\mathrm{b}}$ & $38.673 \pm 2.231$ & $38.339 \pm 3.201$ & $39.679 \pm 2.388$ & $39.544 \pm 2.518$ \\
\hline$\omega-6$ & $7.202 \pm 0.862$ & $12.650 \pm 2.766^{*}$ & $6.863 \pm 0.338$ & $8.095 \pm 1.397$ \\
\hline$\omega-3$ & $2.708 \pm 0.311$ & $2.711 \pm 0.193$ & $4.591 \pm 0.732^{*}$ & $3.872 \pm 0.358^{*}$ \\
\hline$\omega-6 / \omega-3$ & $2.735 \pm 0.234$ & $4.576 \pm 0.579 * *$ & $1.577 \pm 0.183^{* *}$ & $2.122 \pm 0.374$ \\
\hline Fold increase $^{c}$ & & 2.403 & 2.116 & 2.199 \\
\hline
\end{tabular}

HT29 cells were left untreated (CTRL) or treated with AA, DHA, EPA (50 $\mu \mathrm{M}$ for $48 \mathrm{~h})$.

aSFA: saturated fatty acids; ${ }^{b}$ MUFA: mono-unsaturated fatty acids.

'Fold increase: AA, DHA or EPA in treated cells versus AA, DHA or EPA in untreated cells, respectively.

Data are presented as percentage of total fatty acids, mean \pm SE $(n=4)$. Significance versus CTRL: ${ }^{*} p<0.05 ;{ }^{* *} p<0.01$.

they were direct activators of $\operatorname{Trc} 8$ and/or gp78. To confirm this hypothesis, we set up a cell-free system, containing the human recombinant HMGCoAR protein, the E2 ubiquitin conjugating enzyme Ube2g2, which mediates the degradation of several ER-associated proteins [49] including HMGCoAR [40], and the recombinant gp78 or Trc8 proteins. DHA and EPA dose-dependently increased the ubiquitination of HMGCoAR by activating the Ube2g2Trc8 system. Since Trc8 was more expressed in HT29 cells, where DHA and EPA did not increase the ubiquitination of HMGCoAR, we may speculate that Trc8 works at its maximal rate in chemosensitive cells and cannot be further activated by $\omega 3$ PUFAs. By contrast, in HT29-dx cells, where the amount of $\operatorname{Trc} 8$ was lower, the activating effect of DHA and EPA became more evident. To our knowledge, this is the first work reporting that $\omega 3$ PUFAs activate the E3 ligase Trc8. This observation also provides mechanistic insights to explain previous works, reporting that DHA increases the activity of ERAD system [23,24], and the proteasomal degradation of specific proteins in colon cancer [50]. Contrarily to DHA and EPA, AA had no effect on $\operatorname{Trc} 8$, in keeping with its inefficacy in reducing HMGCoAR and cholesterol synthesis. w3PUFAs and $\omega 6$ PUFAs have different conformation and steric hindrance; these factors can determine the selective interactions with target proteins and the specificity of their effects.
A striking consequence of down-regulating cholesterol synthesis in HT29-dx cells is the reduction of the cholesterol amount in DRMs, which we extracted as described [51,52]. It has been reported that DRMs contain about 40\% of Pgp in drug-resistant HT29 cells [53]. Pgp, MRP1 and BCRP associated with DRMs are active and the peculiar physicochemical properties of DRM domains - such as the presence of cholesterol - preserve the transporters activity $[29,30,53,54]$. The depletion of cholesterol from DRMs indeed induces the shift of Pgp into soluble cell fractions and the decrease of its activity [54]. This observation is in keeping with the decrease of surface- and DRMassociated Pgp that we observed in HT29-dx cells treated with EPA and DHA. The decrease of surface Pgp was not accompanied by a reduced amount of Pgp in whole cell lysates, suggesting that $\omega 3$ PUFAs do not modulate the expression of Pgp, but only its intracellular distribution. To our knowledge, the shift of MRP1 from DRMs into cytosol following cholesterol depletion has not been described yet. In HT29-dx cells, the surface level of MRP1 was also decreased by $\omega 3$ PUFAs, suggesting that the localization of this transporter may be sensitive as well to the amount of cholesterol present in the plasma-membrane.

Beside lowering the amount of cholesterol, PUFAs were effectively incorporated in whole cells and DRMs of HT29 and HT29-dx cells even if with different efficiency. Recent works performed on reconstructed membranes and B 
Table 4 Detergent resistant membrane (DRM) fatty acids composition of HT29-dx cells

\begin{tabular}{|c|c|c|c|c|}
\hline & CTRL & $A A$ & DHA & EPA \\
\hline C16:0 & $33.091 \pm 2.128$ & $31.588 \pm 1.305$ & $32.446 \pm 2.793$ & $35.242 \pm 1.836$ \\
\hline C16:1 & $9.598 \pm 0.716$ & $9.155 \pm 0.742$ & $7.628 \pm 2.111$ & $9.443 \pm 1.181$ \\
\hline C18:0 & $14.605 \pm 0.786$ & $14.957 \pm 0.709$ & $16.538 \pm 1.964$ & $17.281 \pm 0.933$ \\
\hline C18:1 & $31.885 \pm 1.922$ & $30.603 \pm 1.864$ & $29.766 \pm 2.366$ & $30.369 \pm 2.772$ \\
\hline C18:2 & $3.511 \pm 0.512$ & $3.059 \pm 0.934$ & $3.107 \pm 0.770$ & $2.950 \pm 0.340$ \\
\hline C18:3 $\omega-3$ & $0.351 \pm 0.028$ & $0.630 \pm 0.052^{*}$ & $0.460 \pm 0.011 \S \S$ & $0.480 \pm 0.057$ \\
\hline C18:3 $\omega-6$ & $0.480 \pm 0.160$ & $0.540 \pm 0.183$ & $0.455 \pm 0.156$ & $0.435 \pm 0.226$ \\
\hline C20:3 & $0.876 \pm 0.059$ & $0.700 \pm 0.055$ & $0.692 \pm 0.032$ & $0.654 \pm 0.059$ \\
\hline C20:4 (AA) & $2.978 \pm 0.266$ & $7.599 \pm 0.421^{* * *}$ & $3.093 \pm 0.403$ & $2.829 \pm 0.395$ \\
\hline C20:5 (EPA) & $0.711 \pm 0.053$ & $0.717 \pm 0.396$ & $1.113 \pm 0.214$ & $3.498 \pm 1.205^{* *}$ \\
\hline C22:5 & $0.595 \pm 0.141$ & $0.507 \pm 0.089$ & $1.011 \pm 0.619$ & $0.481 \pm 0.201$ \\
\hline C22:6 (DHA) & $1.320 \pm 0.113$ & $1.365 \pm 0.113$ & $4.500 \pm 1.286^{* *}$ & $1.258 \pm 0.104$ \\
\hline $\mathrm{SFA}^{\mathrm{a}}$ & $47.696 \pm 2.853$ & $46.545 \pm 1.903$ & $48.984 \pm 4.545$ & $48.203 \pm 5.614$ \\
\hline MUFA $^{\mathrm{b}}$ & $41.483 \pm 2.452$ & $39.759 \pm 2.546$ & $37.394 \pm 3.993$ & $39.812 \pm 3.942$ \\
\hline$\omega-6$ & $7.364 \pm 0.609$ & $10.403 \pm 0.498^{*}$ & $6.891 \pm 0.643$ & $6.433 \pm 0.401$ \\
\hline$\omega-3$ & $2.977 \pm 0.266$ & $3.218 \pm 0.270$ & $7.490 \pm 1.974^{*}$ & $5.878 \pm 1.461^{*}$ \\
\hline$\omega-6 / \omega-3$ & $2.680 \pm 0.160$ & $3.141 \pm 0.309$ & $1.055 \pm 0.287^{*}$ & $1.312 \pm 0.378$ \\
\hline Fold increase $e^{c}$ & & 2.758 & 3.024 & 4.821 \\
\hline
\end{tabular}

HT29-dx cells were left untreated (CTRL) or treated with AA, DHA, EPA (50 $\mu \mathrm{M}$ for $48 \mathrm{~h}$ ).

${ }^{a}$ SFA: saturated fatty acids; ${ }^{b}$ MUFA: mono-unsaturated fatty acids.

${ }^{C}$ Fold increase: AA, DHA or EPA in treated cells versus AA, DHA or EPA in untreated cells, respectively.

Data are presented as percentage of total fatty acids, mean \pm SE $(n=4)$. Significance versus CTRL: ${ }^{*} p<0.05 ;{ }^{* *} p<0.01$; versus the corresponding treatment in HT29 cells: $\S \S p<0.01$.

lymphocytes described a higher incorporation of DHA compared to EPA in whole cell lipids, in detergent-soluble membranes and DRMs [55-57]. In HT29 cells, whereas EPA and DHA were inserted at a similar extent in DRMs, EPA was more greatly incorporated than DHA in whole cell lipids. Such discrepancy with the situation observed in B lymphocytes may be due to different protocols of treatment and different metabolism of $\omega 3$ PUFAs in the two cell types [46]. For instance, after 15 hours of treatment, an higher increase of DPA, a metabolite derived from EPA, was observed in B lymphocytes [56]. Interestingly, the sum of EPA and DPA incorporated in B lymphocyte membranes [56] is in the same range of EPA incorporation measured in HT29 and HT29-dx cells, wherein EPA is poorly metabolized into DPA. This is not surprising, because different cell types have different rate of uptake, metabolism and incorporation of $\omega 3$ PUFAs [46]. It is conceivable that the enzymatic activity of the elongase which metabolizes EPA into DPA is low in our cell lines, making the availability of EPA and its consequent incorporation in cell membranes higher than in other cell models.

Table 5 Median and mean fluorescence intensity (MFI) of surface Pgp, MRP1 and BCRP in HT29 and HT29-dx cells

\begin{tabular}{ccccccc}
\hline Sample & $\begin{array}{c}\text { Pgp } \\
\text { Median }\end{array}$ & $\begin{array}{c}\text { Pgp } \\
\text { MFI }\end{array}$ & $\begin{array}{c}\text { MRP1 } \\
\text { Median }\end{array}$ & $\begin{array}{c}\text { MRP1 } \\
\text { MFI }\end{array}$ & $\begin{array}{c}\text { BCRP } \\
\text { Median }\end{array}$ & $\begin{array}{c}\text { BCRP } \\
\text { MFI }\end{array}$ \\
\hline HT29 CTRL & $8.24 \pm 0.59$ & $7.21 \pm 0.11$ & $5.15 \pm 0.43$ & $4.61 \pm 0.41$ & $5.37 \pm 0.25$ & $4.71 \pm 0.26$ \\
HT29 AA & $10.02 \pm 2.25$ & $8.58 \pm 1.11$ & $6.35 \pm 0.54$ & $5.52 \pm 0.36$ & $6.80 \pm 0.21$ & $5.62 \pm 0.37$ \\
HT29 DHA & $14.93 \pm 2.02$ & $8.74 \pm 0.92$ & $5.49 \pm 0.29$ & $5.25 \pm 0.44$ & $7.12 \pm 0.47$ & $6.49 \pm 0.36$ \\
HT29 EPA & $11.73 \pm 1.01$ & $10.09 \pm 0.98$ & $6.00 \pm 0.47$ & $6.55 \pm 0.34$ & $6.15 \pm 0.29$ & $5.57 \pm 0.19$ \\
HT29-dx CTRL & $34.84 \pm 3.66^{*}$ & $31.06 \pm 3.52^{*}$ & $34.01 \pm 2.15^{*}$ & $32.20 \pm 1.08^{*}$ & $5.15 \pm 0.23$ & $4.96 \pm 0.23$ \\
HT29-dx AA & $48.83 \pm 4.72^{*}$ & $43.32 \pm 4.98^{*}$ & $44.04 \pm 5.53^{*}$ & $41.05 \pm 5.11^{*}$ & $7.74 \pm 0.83$ & $7.23 \pm 0.41$ \\
HT29-dx DHA & $6.41 \pm 0.52^{\circ}$ & $5.83 \pm 0.41^{\circ}$ & $3.38 \pm 0.41^{\circ}$ & $3.16 \pm 0.37^{\circ}$ & $7.69 \pm 0.79$ & $7.23 \pm 0.59$ \\
HT29-dx EPA & $8.26 \pm 0.51^{\circ}$ & $7.50 \pm 0.21^{\circ}$ & $3.31 \pm 0.24^{\circ}$ & $2.89 \pm 0.13^{\circ}$ & $8.17 \pm 0.89$ & $7.64 \pm 0.48$ \\
\hline
\end{tabular}

HT29 and HT29-dx cells were left untreated (CTRL) or treated with AA, DHA, EPA $(50 \mu \mathrm{M}$ for $48 \mathrm{~h})$.

Data were calculated with the Cell Quest software and are presented as mean $\pm S D(n=3)$. Versus CTRL HT29: ${ }^{*} p<0.002$; versus CTRL HT29-dx: ${ }^{\circ} p<0.001$. 


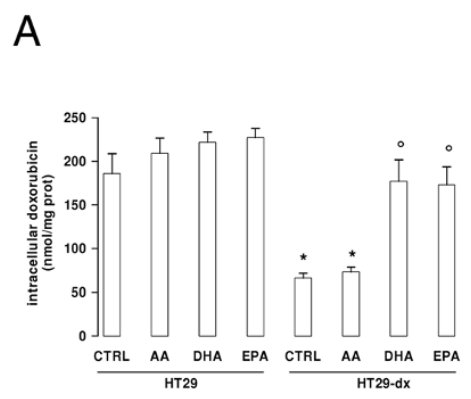

B
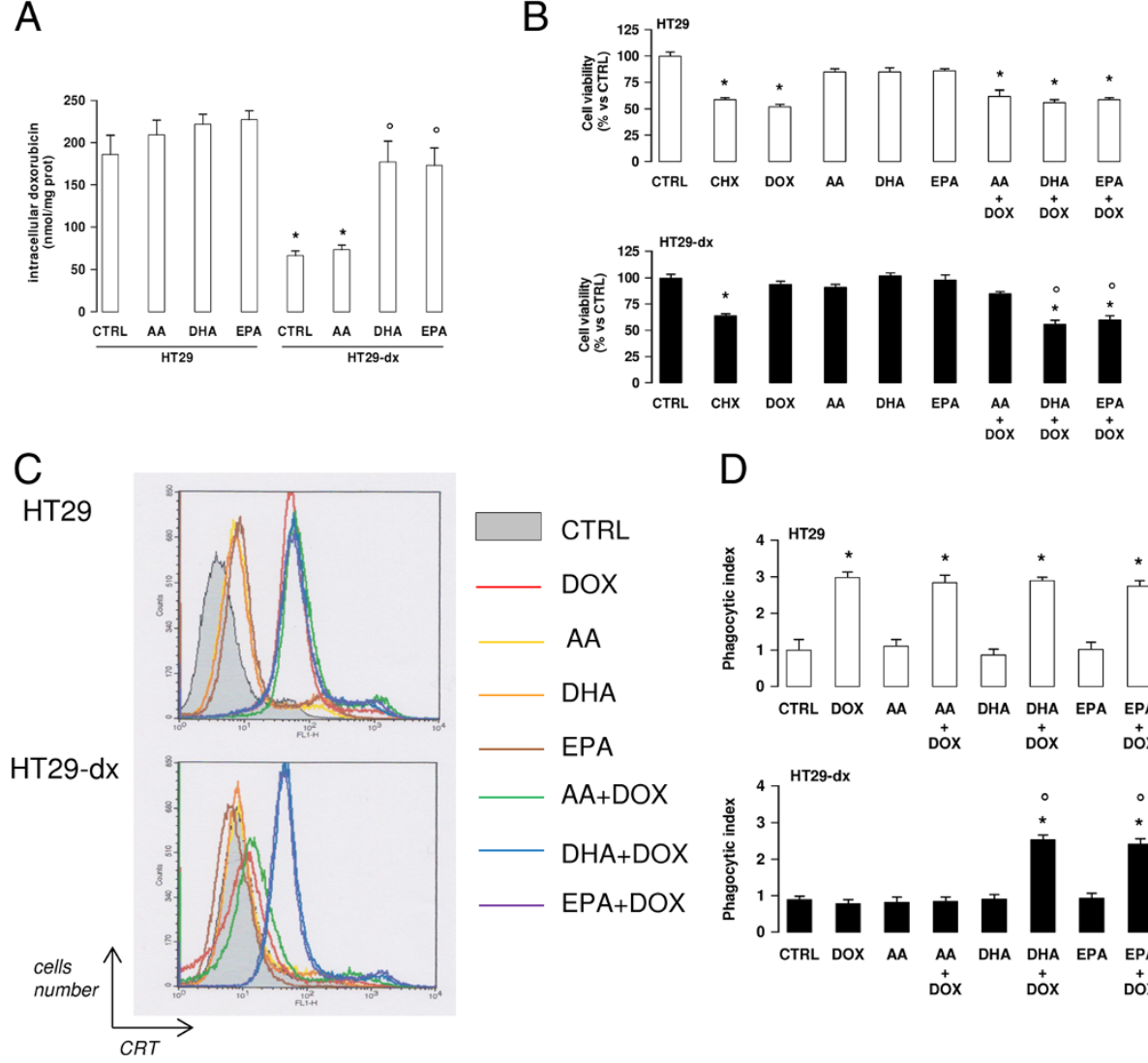

$\mathrm{D}$
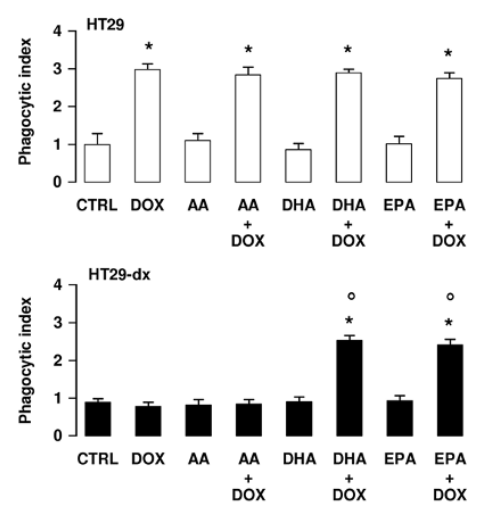

Figure 6 w3PUFAs restore doxorubicin cytotoxicity in chemoresistant colon cancer cells. HT29 and HT29-dx cells were incubated for $48 \mathrm{~h}$ in the absence (CTRL) or in the presence of $50 \mu \mathrm{M}$ arachidonic acid (AA), docosahexaenoic acid (DHA), eicosapentaenoic acid (EPA). $5 \mu \mathrm{M}$ doxorubicin (DOX) was added for $24 \mathrm{~h}$, alone or during the last $24 \mathrm{~h}$ of incubation with fatty acids. Cycloheximide ( $4 \mu \mathrm{M}$ for $24 \mathrm{~h}, \mathrm{CHX}$ ) was chosen as positive control of cytotoxicity in both chemosensitive and chemoresistant cells. (A) The intracellular accumulation of doxorubicin was measured fluorimetrically in duplicate. Data are presented as means $\pm S D(n=3)$. Versus CTRL HT29: * $p<0.005$; versus CTRL HT29-dx: ${ }^{\circ} p<0.005$. (B) Cells were stained with Neutral Red solution and the absorbance of viable cells was measured in triplicate spectrophotometrically. Data are presented as means $\pm S D(n=4)$. Versus respective CTRL: ${ }^{*} p<0.002$; versus DOX alone: ${ }^{\circ} p<0.005$. (C) Surface levels of calreticulin were measured in non-permeabilized cells by flow cytometry. The figures shown here are representative of three similar experiments, performed in triplicate. (D) The phagocytosis rate by DCs was evaluated in duplicate by flow cytometry. Data are presented as means $\pm S D(n=4)$. Versus respective CTRL: ${ }^{*}<<0.05$; versus DOX alone: $p<0.005$.

There is a general agreement that DHA actively modifies the DRMs organization, producing DRMs disassembly and cholesterol displacement, inducing lateral phase separation into PUFA-rich/sterol-poor microdomains and impairing the activity of many DRM-associated proteins $[34,36]$. Pgp is one of these proteins, since its activity is significantly reduced when the lipid environment of DRMs is altered [58]. Together with the effects on cholesterol synthesis, the incorporation of EPA and DHA in DRM phospholipids is a second mechanisms by which $\omega 3$ PUFAs decrease the levels of Pgp and MRP1 in HT29-dx cells.

According to its structure, BCRP is less hydrophobic than Pgp and MRP1 [27]. We cannot exclude that - differently from what we observed for Pgp and MRP1 - the enrichment of $\omega 3$ PUFAs and $\omega 6$ PUFAs may favor the retention of BCRP in DRMs compartment. In particular the enrichment of DHA seemed the most suitable condition to increase BCRP levels in DRMs, in both HT29 and
HT29-dx cells. Since the first-line drugs used in the treatment of colon cancer (e.g. irinotecan, oxaliplatin, 5fluorouracil) are not substrates of BCRP, we do not believe that the increase of BCRP may negatively affect the outcome of patients subjected to the standard chemotherapeutic regimen for colon cancer.

By contrast, in consequence of the decreased surface levels of Pgp and MRP1, DHA and EPA overcame chemoresistance to doxorubicin, a substrate of these two transporters [27], and to irinotecan, a substrate of Pgp [44]. A similar effect was produced by DHA and EPA in the Pgpoverexpressing Caco-2 cells treated with paclitaxel [59]. DHA and EPA fully restored both the direct cytotoxicity and the "indirect" pro-immunogenic toxicity of doxorubicin, i.e. they decreased the cell viability, and increased the release of ATP and HMGB1, the translocation of calreticulin and the phagocytosis. Calreticulin expression is usually associated with good prognosis in patients with advanced- 
Table 6 Median and mean fluorescence intensity (MFI) of surface calreticulin (CRT) in HT29 and HT29-dx cells

\begin{tabular}{lcc}
\hline Sample & $\begin{array}{c}\text { CRT } \\
\text { Median }\end{array}$ & CRT \\
\hline HT29 CTRL & $4.96 \pm 0.17$ & MFI \\
HT29 DOX & $57.59 \pm 4.87^{*}$ & $53.28 \pm 0.32$ \\
HT29 AA & $8.50 \pm 1.69$ & $7.37 \pm 0.96$ \\
HT29 DHA & $9.51 \pm 2.14$ & $7.57 \pm 0.84$ \\
HT29 EPA & $10.84 \pm 2.39$ & $8.74 \pm 1.28$ \\
HT29 AA + DOX & $65.44 \pm 4.91^{*}$ & $67.17 \pm 6.32^{*}$ \\
HT29 DHA + DOX & $70.40 \pm 4.85^{*}$ & $58.82 \pm 4.82^{*}$ \\
HT29 EPA + DOX & $68.16 \pm 5.13^{*}$ & $59.35 \pm 3.31^{*}$ \\
HT29-dx CTRL & $8.99 \pm 1.89$ & $8.51 \pm 0.27$ \\
HT29-dx DOX & $10.08 \pm 2.78$ & $10.09 \pm 0.31$ \\
HT29-dx AA & $11.41 \pm 2.49$ & $9.06 \pm 0.97$ \\
HT29-dx DHA & $10.85 \pm 2.11$ & $8.66 \pm 0.41$ \\
HT29-dx EPA & $6.77 \pm 0.82$ & $6.55 \pm 0.53$ \\
HT29-dx AA + DOX & $17.68 \pm 5.15$ & $14.72 \pm 4.66$ \\
HT29-dx DHA + DOX & $56.74 \pm 4.60^{* \circ}$ & $46.56 \pm 2.64^{* \circ}$ \\
HT29-dx EPA + DOX & $56.25 \pm 5.21^{* \circ}$ & $44.11 \pm 3.61^{* \circ}$ \\
\hline
\end{tabular}

HT29 and HT29-dx cells were left untreated (CTRL) or treated with AA, DHA, EPA $(50 \mu \mathrm{M}$ for $48 \mathrm{~h}$ ).

Data were calculated with the Cell Quest software and are presented as mean \pm $\mathrm{SD}(\mathrm{n}=3)$. Versus CTRL HT29: * $\mathrm{p}<0.001 ; \mathrm{HT} 29-\mathrm{dx}$ DHA + DOX/EPA + DOX versus HT29-dx DOX: ${ }^{\circ} p<0.002$

stage colon cancer, and correlates with a proper antitumor response of the host immune system [60]. We demonstrated that the association of $\omega 3$ PUFAs and doxorubicin enhanced the exposure of calreticulin in colon chemoresistant cells. Although doxorubicin is not currently used in colon cancer therapy, our work suggests that the combination of $\omega 3$ PUFAs and doxorubicin might be noteworthy of further studies to set up effective chemo-immunotherapy protocols in colon cancer, a disease in which immunebased interventions are under clinical investigation [61,62]. Irinotecan is currently used in colon cancer treatment. Our results, showing that DHA and EPA lowered the IC50 of irinotecan and completely restored its anti-proliferative effects in HT29-dx cells, may have a translational potential in clinical settings.

The chemosensitizing effect of DHA and EPA has been already described in HT29 cells, where they enhance the pro-apoptotic effects of irinotecan, oxaliplatin and 5fluorouracil [63]. Our study is the first describing the efficacy of $\omega 3$ PUFAs in chemoresistant colon cancer cells. The mechanism that we propose for such chemosensitization - i.e. the inhibition of $A B C$ transporters activity might help to explain why a dietary supplementation with $\omega 3$ PUFAs improves the efficacy of irinotecan in mice bearing colon cancer [64], the efficacy of anthracyclines in patients with breast cancer [65], the efficacy of cisplatin plus

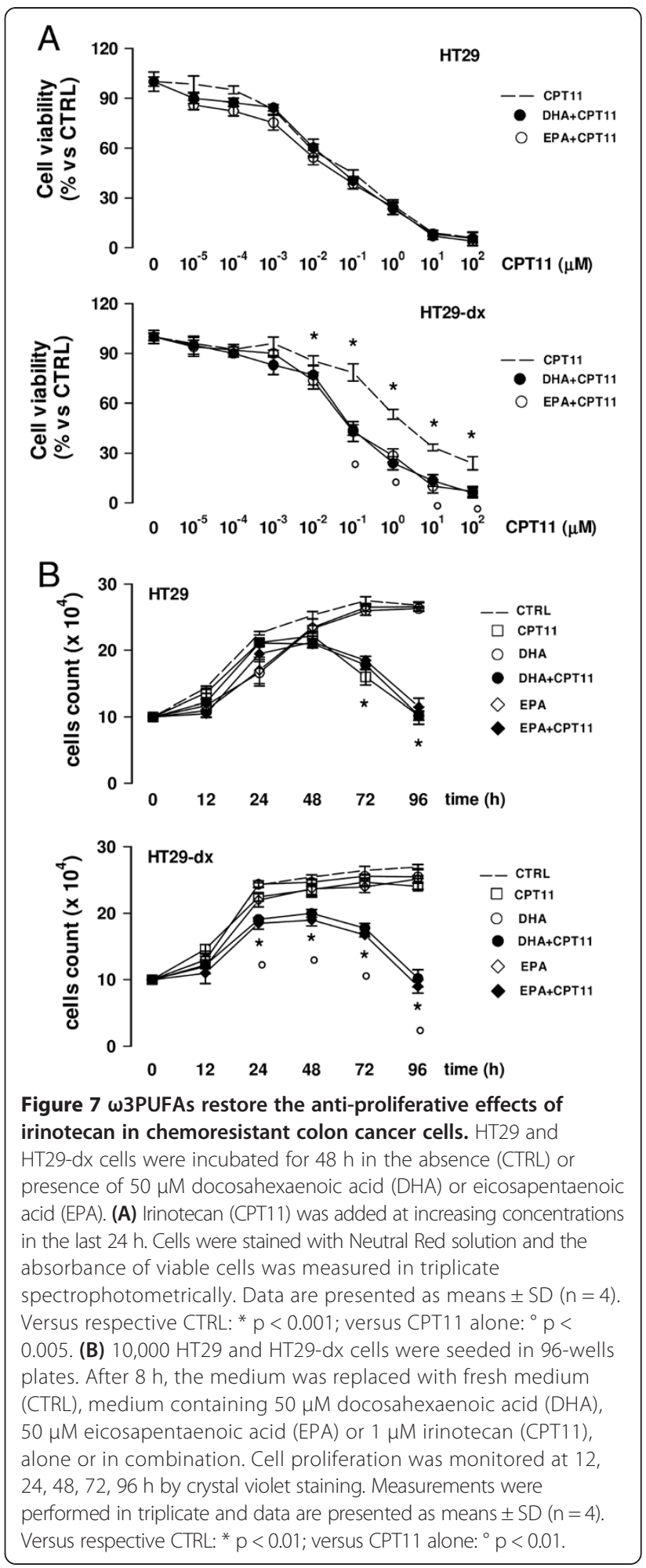

vinorelbine in patients with non small cell lung cancer [66]. Moreover our work provides the biochemical mechanism explaining why vincristine, a substrate of Pgp and MRP1, was less effluxed by drug-resistant human cervical cancer $\mathrm{KB}-\mathrm{Ch}^{\mathrm{R}}-8-5$ cells treated with $\omega 3$ PUFAs [67]. 


\section{Conclusions}

We describe here a new effect of $\omega 3$ PUFAs, i.e. the down-regulation of the endogenous cholesterol synthesis by promoting HMGCoAR ubiquitination via Trc8 E3 ligase. Such effect is particularly pronounced in cells with a dysregulated cholesterol synthesis - i.e. with high demand of cholesterol, high intracellular levels of cholesterol, high amount of HMGCoAR - such as MDR cells. The decreased amount of cholesterol and the increased incorporation of w3PUFAs in DRMs alter the physicochemical properties of these compartments that are essential for the proper localization and activity of $A B C$ transporters. As a result of these events, $\omega 3$ PUFAs overcome drug resistance towards substrates of Pgp and MRP1, and restore a proper tumor-immune system recognition in response to chemotherapy in MDR cells (Additional file 5).

The effects of $\omega 3$ PUFAs are likely not limited to colon cancer cells, because the increased demand of cholesterol is a typical feature of several types of chemoresistant tumors $[25,26]$.

A diet rich of saturated fatty acids increases, whereas a diet rich of $\omega 3$ PUFAs decreases the onset of colon cancer. Whereas the chemopreventing effects of $\omega 3$ PUFAs are well-documented in colon cancer [11-16], their effects as MDR-overcoming agents have not been reported previously in this tumor. Compared with other chemosensitizing agents affecting the synthesis of cholesterol e.g. statins, aminobisphosphonates - [25,26], $\omega 3$ PUFAs are safer and have less side-effects. Therefore, a dietetic supplementation with $\omega 3$ PUFAs may be regarded not only as a useful chemopreventive strategy, but also as a potential adjuvant approach in patients with colon cancers unresponsive to chemotherapy.

\section{Methods}

Chemicals

Fetal bovine serum (FBS) and culture medium were purchased from Invitrogen Life Technologies (Carlsbad, CA). Plasticware for cell cultures was from Falcon (Becton Dickinson, Franklin Lakes, NJ). AA, DHA, EPA, doxorubicin, irinotecan were from Sigma Chemical Co. (St. Louis, $\mathrm{MO})$. Stock solutions of PUFAs were dissolved in absolute ethanol and added on cell cultures as a mixture PUFAs/ fatty acid free bovine serum albumin (BSA), with a 3:1 ratio. The amount of ethanol added in each dish never exceeded $0.5 \% \mathrm{v} / \mathrm{v}$. Control cells were treated with a $0.5 \% \mathrm{v} / \mathrm{v}$ solution of ethanol. Simvastatin and MG-132 were obtained from Calbiochem (San Diego, CA). Electrophoresis reagents were from Bio-Rad Laboratories (Hercules, CA). The protein content of cell monolayers and lysates was assessed with the BCA kit from Sigma Chemical Co. Unless otherwise specified, all the other reagents were from Sigma.

\section{Cells}

Human chemosensitive colon cancer HT29 cells were from ATCC (Rockville, MD). The chemoresistant counterpart (HT29-dx cells) line was generated by culturing parental cells in the presence of increasing concentrations of doxorubicin for 20 passages [41]. HT29-dx cells have higher Pgp, MRP1 and BCRP than HT29 cells [68]; moreover, compared to HT29 cells, HT29-dx cells have a higher IC50 for doxorubicin $(25.51 \pm 1.33 \mu \mathrm{M}$ versus $2.74 \pm 0.67 \mu \mathrm{M}$; $\mathrm{p}<0.01)$, irinotecan $(0.91 \pm 0.18 \mu \mathrm{M}$ versus $0.05 \pm 0.01 \mu \mathrm{M}$; $\mathrm{p}<0.001)$, oxaliplatin $(98.75 \pm 6.08 \mu \mathrm{M}$ versus $4.75 \pm$ $0.71 \mu \mathrm{M} ; \mathrm{p}<0.001)$, and 5-fluorouracil $(8.35 \pm 0.64 \mu \mathrm{M}$ versus $1.06 \pm 0.14 \mu \mathrm{M} ; \mathrm{p}<0.05$ ), representing a reliable model of MDR cells. For the present work, HT29-dx cells were grown in medium containing $200 \mathrm{nM}$ doxorubicin. Cell cultures were maintained in RPMI-1640 medium supplemented with $10 \% \mathrm{v} / \mathrm{v}$ FBS, $1 \% \mathrm{v} / \mathrm{v}$ penicillin-streptomycin and $1 \% \mathrm{v} / \mathrm{v}$ L-glutamine, in a humidified atmosphere at $37^{\circ} \mathrm{C}$ and $5 \% \mathrm{CO}_{2}$. All the experiments with these cell lines were approved by Bioethics Committee ("Comitato di Bioetica d'Ateneo") of the University of Torino, Italy.

\section{De novo synthesis of cholesterol}

Cells were labeled with $1 \mu \mathrm{Ci} / \mathrm{ml}\left[{ }^{3} \mathrm{H}\right]$ acetate $(3600 \mathrm{mCi} /$ mmol; Amersham Bioscience, Piscataway, NJ) and the synthesis of radiolabeled cholesterol was measured as described [69]: after $24 \mathrm{~h}$ the cells were washed twice with phosphate-buffered saline (PBS) and mechanically scraped in $200 \mu \mathrm{l}$ of PBS. $500 \mu \mathrm{l}$ of methanol and $1 \mathrm{ml}$ of hexane were added to the cell suspension, which was stirred at room temperature for $1 \mathrm{~h}$ and then centrifuged at 2,000 $\times \mathrm{g}$ for $5 \mathrm{~min}$. The upper phase containing hexane was transferred into a new test tube, and the lower phase was supplemented with $1 \mathrm{ml}$ of hexane and stirred overnight. After a 5 min centrifugation at $2,000 \times$ g, the upper phase was added to the previous one and the solvent was allowed to evaporate at room temperature for $24 \mathrm{~h}$. Cellular lipid extracts produced by this separation were re-suspended in $30 \mu \mathrm{l}$ of chloroform and then subjected to thin layer chromatography (TLC), using a 1:1 (v/v) ether/hexane solution as mobile phase. Each sample was spotted on pre-coated LK6D Whatman silica gels (Merck, Darmstadt, Germany) and allowed to run for $30 \mathrm{~min}$. Solutions of $10 \mu \mathrm{g} / \mathrm{ml} \mathrm{chol-}$ esterol were used as standard. The silica gel plates were exposed for $1 \mathrm{~h}$ to a iodine-saturated atmosphere, then the migrated spots were cut out and their radioactivity was measured by liquid scintillation, using a Tri-Carb Liquid Scintillation Analyzer (PerkinElmer, Waltham, MA). The results were expressed as fmol $\left[{ }^{3} \mathrm{H}\right]$ cholesterol/mg cell proteins, according to the relative calibration curve.

\section{Cells viability, cytotoxicity and proliferation assays}

In viability assays, cells were seeded in 24-wells plates, treated for $24 \mathrm{~h}$ with AA, DHA and EPA at 25, 50, 100, 
$200 \mu \mathrm{M}$, then incubated for $1 \mathrm{~h}$ at $37^{\circ} \mathrm{C}$ in culture medium containing $70 \mu \mathrm{g} / \mathrm{ml}$ of Neutral Red solution (Sigma). Cells were washed three times with PBS and rinsed with stop buffer (32 $\mathrm{mM}$ trisodium citrate, $50 \% \mathrm{v} / \mathrm{v}$ methanol; $\mathrm{pH} 6$ ). The absorbance at $540 \mathrm{~nm}$ was read using a Synergy HT Multi-Detection Microplate Reader (Bio-Tek, Winooski, VT). The absorbance of untreated cells was considered as $100 \%$ viability; the results were expressed as percentage of viable cells versus untreated cells.

The percentage of annexin-V-positive cells, considered as apoptotic cells, was measured as previously reported [69]: cells were treated for $24 \mathrm{~h}$ with $50 \mu \mathrm{M} \mathrm{AA}$, DHA or EPA, washed twice with fresh PBS, detached with $200 \mu \mathrm{l}$ of Cell Dissociation Solution (Sigma) for $10 \mathrm{~min}$ at $37^{\circ} \mathrm{C}$ and re-suspended in $500 \mu \mathrm{l}$ of binding buffer (100 mM Hepes, $140 \mathrm{mM} \mathrm{NaCl}, 25 \mathrm{mM} \mathrm{CaCl}_{2}$, $\mathrm{pH}$ 7.5). Each sample was incubated with $10 \mu \mathrm{M}$ Annexin V-fluorescein isothiocyanate (FITC) for $5 \mathrm{~min}$ at room temperature and the fluorescence was recorded using a FACSCalibur system (Becton Dickinson Biosciences, San Jose, CA), with a $530 \mathrm{~nm}$ band pass filter. For each analysis 10,000 events were collected and the percentage of cells positive for Annexin V-FITC was calculated by the Cell Quest software (Becton Dickinson Biosciences).

The extracellular release of high-mobility group 1 box (HMGB1) protein was taken as index of necrotic and immunogenic death, the extracellular release of ATP was considered an index of immunogenic death. To measure the extracellular release of HMGB1, $20 \mu \mathrm{l}$ of the cell culture medium were boiled, resolved by SDS-PAGE and probed with an anti-HMGB1 antibody (Sigma). Blots were pre-stained with Red Ponceau to check the equal loading of proteins. The ATP release was measured on $100 \mu \mathrm{l}$ of the cell culture medium with the ATP Bioluminescent Assay Kit (FL-AA, Sigma Aldrich Co.), using a Synergy HT Multi-Detection Microplate Reader. The results were expressed as nmol ATP/mg protein, according to the titration curve previously set.

In proliferation assays, 10,000 cells were seeded in 96-wells plates and treated with $1 \mu \mathrm{M}$ irinotecan, $50 \mu \mathrm{M}$ DHA, $50 \mu \mathrm{M}$ EPA, alone or in co-incubation. At $12,24,48,72,96 \mathrm{~h}$, cells were fixed with $4 \% \mathrm{w} / \mathrm{v}$ paraformaldehyde and stained with $0.5 \% \mathrm{w} / \mathrm{v}$ crystal violet solution for $10 \mathrm{~min}$ at room temperature. The plate was washed three times in water, then $100 \mu \mathrm{l}$ of $0.1 \mathrm{mM}$ sodium citrate in $50 \% \mathrm{v} / \mathrm{v}$ ethanol was added to each well. The absorbance was read at $570 \mathrm{~nm}$ using a Synergy HT Multi-Detection Microplate Reader. The absorbance units were converted into number of cells, according to a titration curve obtained with serial cells dilutions.

\section{HMGCoAR activity}

The activity of HMGCoAR was measured in microsomal fractions as described previously [69]. The cells were rinsed with the lysis buffer $(10 \mathrm{mM}$ Tris, $100 \mathrm{mM}$ $\mathrm{NaCl}, 20 \mathrm{mM} \mathrm{KH} \mathrm{PO}_{4}, 30 \mathrm{mM}$ EDTA, $1 \mathrm{mM}$ EGTA, $250 \mathrm{mM}$ sucrose, $\mathrm{pH}$ 7.5) supplemented with protease inhibitor cocktail set III (100 mM AEBSF, $80 \mathrm{mM}$ aprotinin, $5 \mathrm{mM}$ bestatin, $1.5 \mathrm{mM}$ E- 64, $2 \mathrm{mM}$ leupeptin,1 $\mathrm{mM}$ pepstatin; Calbiochem), $1 \mathrm{mM} \mathrm{Na} \mathrm{VO}_{4}, 1 \mathrm{mM} \mathrm{NaF}$, $1 \mathrm{mM}$ 4-(2-aminoethyl)benzenesulphonyl fluoride (PMSF), $10 \mathrm{mM}$ aprotinin, $10 \mathrm{mM}$ dithiothreitol (DTT). After sonication (2 bursts of $10 \mathrm{~s}$; Labsonic sonicator, Sartorius Stedim Biotech S.A., Aubagne Cedex, France), cell lysates were centrifuged at $13,000 \times \mathrm{g}$ for $15 \mathrm{~min}$ at $4^{\circ} \mathrm{C}$; the supernatants were subjected to ultracentrifugation at $100,000 \times \mathrm{g}$ for $1 \mathrm{~h}$ at $4^{\circ} \mathrm{C}$, using a Optima L-90 K Beckman Coulter Ultracentrifuge (Beckman Coulter Inc, Fullerton, CA) to collect the microsomal fraction, which was resuspended in $250 \mu \mathrm{l}$ of lysis buffer and stored at $-80^{\circ} \mathrm{C}$ until the use. $12.5 \mu \mathrm{g}$ of microsomal protein extracts, resuspended in $25 \mu \mathrm{l}$, were supplemented with $10 \mathrm{mM}$ DTT, $5 \mathrm{mM}$ NADP and with a NADPH-generating system (1.3 mM glucose 6-phosphate, $0.67 \mathrm{U} / \mathrm{ml}$ of glucose-6phosphate dehydrogenase, $33 \mathrm{mM} \mathrm{MgCl}_{2}$ ). The reaction was started by adding $60 \mathrm{nCi}\left[{ }^{14} \mathrm{C}\right] \mathrm{HMG}-\mathrm{CoA}(50-62 \mathrm{mCi} /$ mmol, Amersham Bioscience). After a $20 \mathrm{~min}$ incubation at $37^{\circ} \mathrm{C}$ the reaction was stopped with $25 \mu \mathrm{l}$ of $10 \mathrm{~N} \mathrm{HCl}$. The samples were stirred for $30 \mathrm{~min}$ at $37^{\circ} \mathrm{C}$ to enhance the complete lactonization of mevalonic acid, centrifuged at $13,000 \times \mathrm{g}$ for $2 \mathrm{~min}$ and separated by TLC on silica gel plates with hexane/acetone $(1: 1, \mathrm{v} / \mathrm{v})$ as mobile phase. A $1 \mathrm{mM}$ solution of purified mevalonolactone was used as standard. The labeled product $\left({ }^{14} \mathrm{C}\right.$-mevalonolactone) was recovered from the TLC plates and quantified by liquid scintillation. The results were expressed as nmol $\left[{ }^{14} \mathrm{C}\right]$ $\mathrm{HMGCoA} / \mathrm{min} / \mathrm{mg}$ cell proteins, according to the relative calibration curve.

\section{Quantitative Real Time-PCR (qRT-PCR)}

Total RNA was extracted and reverse-transcribed using the QuantiTect Reverse Transcription Kit (Qiagen, Hilden, Germany). RT-PCR was carried out with IQ ${ }^{\mathrm{Tm}}$ SYBR Green Supermix (Bio-Rad). The same cDNA preparation was used for the quantitation of HMGCoAR, HMGCoAS and actin, chosen as a housekeeping gene. The sequences of primers were: HMGCoAR: 5'-CGCAACCTCTATAT CCGT-3'; 5'-GTAGCCGCCTATGCTC-3'; HMGCoAS: 5' -TTGGTAGTTGCAGGAGACATCGCT-3'; 5' -AG CATTTGGCCCAATTAGCAGAGC-3'; actin: 5'-GC TATCCAGGCTGTGCTATC-3'; 5' -TGTCACGCACG ATTTCC-3'. The relative quantitation of each sample was performed by comparing each PCR product with the housekeeping PCR product, using the Software Gene Expression Quantitation (Bio-Rad). 


\section{Western blot analysis}

For total, phosphorylated or ubiquitinated HMGCoAR Western blot analysis, $50 \mu \mathrm{g}$ of microsomal proteins, collected as reported above, were immunoprecipitated with an anti-HMGCoAR antibody (Santa Cruz Biotechnology, Santa Cruz, CA), in the presence of $100 \mathrm{mM}$ DTT and $1 \mathrm{mM}$ mevalonic acid. For total HMGCoAR, the immunoprecipitated samples were separated by SDS-PAGE, transferred to polyvinylidene fluoride membrane sheets (Immobilon-P, Millipore, Bedford, MA) and probed with an anti-HMGCoAR antibody, followed by the peroxidase-conjugated secondary antibody (Bio-Rad). To detect HMGCoAR phosphorylated on serine, blots were incubated with a biotinylated anti-phosphoserine antibody (Sigma), followed by a streptavidin/horseradish peroxidase-conjugated polymer (Sigma). For ubiquitinated HMGCoAR, blots were probed with an antiubiquitin antibody (Enzo Life Science, Farmingdale, NY), followed by the peroxidase-conjugated secondary antibody. The levels of calreticulin, detected by a specific antibody (ABR Affinity Bioreagents, Thermo Scientific, Waltham, MA), were measured to check to equal loading of microsomal proteins. Blot proteins were detected by enhanced chemiluminescence (PerkinElmer).

To analyze the expression of Insig-1, Insig-2, gp78/ AMFR, Trc8/RNF-139, $20 \mu \mathrm{g}$ of the microsomal extracts were probed with the following antibodies: antiInsig-1 (Abcam, Cambridge, MA), anti-Insig-2 (Abcam), anti-gp78/AMFR (GeneTex Inc., Irvine, CA), anti-Trc8/ RNF-139 (Abnova, Taipei City, Taiwan).

Whole cell lysates were used for the Western blot analysis of Pgp, MRP1, BCRP. Cells were lysed in $\mathrm{Mg}^{2+}$ Lysis/ Wash Buffer (125 mM Tris- $\mathrm{HCl}, 750 \mathrm{mM} \mathrm{NaCl}, 1 \% \mathrm{v} / \mathrm{v}$ NP40, 10\% v/v glycerol, $50 \mathrm{mM} \mathrm{MgCl}_{2}, 5 \mathrm{mM}$ EDTA, $25 \mathrm{mM} \mathrm{NaF}, 1 \mathrm{mM} \mathrm{Na} \mathrm{VO}_{4}, 10 \mu \mathrm{g} / \mathrm{ml}$ leupeptin, $10 \mu \mathrm{g} / \mathrm{ml}$ pepstatin, $10 \mu \mathrm{g} / \mathrm{ml}$ aprotinin, $1 \mathrm{mM}$ PMSF, pH 7.5), sonicated and centrifuged at $13,000 \times \mathrm{g}$ for $10 \mathrm{~min}$ at $4^{\circ} \mathrm{C}$. $30 \mu \mathrm{g}$ cell lysates were subjected to Western blotting with anti-Pgp (Calbiochem), anti-MRP1 (Abcam), antiBCRP (Santa Cruz Biotechnology Inc.), anti-tubulin (Santa Cruz Biotechnology Inc.) antibodies. For DRMs samples, $5 \mu \mathrm{g}$ of proteins from DRM fractions (see below) were probed in Western blot analysis with antiPgp, anti-MRP1, anti-BCRP, anti-flotillin (Abcam) or anti-clathrin heavy chain (Abcam) antibodies.

Nucleus-cytosol separation was performed by using the Nuclear Extract kit (Active Motiv, La Hulpe, Belgium). $10 \mu \mathrm{g}$ of nuclear extracts were subjected to Western blot analysis, using anti-SREBP-1, anti-SREBP2 or anti-proliferating cell nuclear antigen (PCNA) antibody (Santa Cruz Biotechnology Inc.).

The densitometric analysis of Western blots was performed with the ImageJ software (http://rsb.info.nih. gov/ij/). Results were expressed as arbitrary units, where ' 1 unit' is the mean band density in untreated cells.

\section{HMGCoAR ubiquitination assay}

To measure the ubiquitination of HMGCoAR, microsomal compartments were isolated from cell as described above. The ubiquitination assay was performed using the E3Lite Customizable Ubiquitin Ligase kit (LifeSensors Inc., Malvern, PA): $100 \mu \mathrm{g}$ of microsomal proteins were diluted in $100 \mu \mathrm{l}$ of ubiquitination assay buffer ( $1 \mathrm{M}$ Tris $/ \mathrm{HCl}, 500 \mathrm{mM} \mathrm{MgCl}_{2}, 10 \mathrm{mM}$ DTT, $\mathrm{pH} 8$ ), and incubated for $30 \mathrm{~min}$ at $37^{\circ} \mathrm{C}$, in the presence of $5 \mathrm{nM}$ E1 activating enzyme provided by the kit, 100 nM E2 conjugating enzyme Ube2g2 (LifeSensors Inc.), $200 \mu \mathrm{M}$ ATP, $6 \mathrm{mM}$ human recombinant ubiquitin. When indicated, $1 \mu \mathrm{M}$ AA, DHA or EPA were added. Samples were washed twice with PBS-Tween $0.1 \% \mathrm{v} / \mathrm{v}$ containing $5 \% \mathrm{w} / \mathrm{v}$ BSA and immunoprecipitated with the antiHMGCoAR antibody. The immunoprecipitated samples were then incubated with the biotinylated anti-ubiquitin antibody of the kit, followed by the streptavidin/horseradish peroxidase-conjugated polymer and enhanced chemiluminescence detection reagent. The chemiluminescent signal was read using a Synergy HT Multi-Detection Microplate Reader. A blank was performed in the absence of microsomal extracts and its luminescence was subtracted from the luminescence of each sample. The results were expressed as relative luminescence units (RLU)/mg of microsomal proteins.

To measure the ubiquitination of HMGCoAR in cell-free systems, $1 \mu \mathrm{g}$ of human recombinant HMGCoAR (catalytic domain, GST-fusion protein produced in E. coli, Sigma), dissolved in $100 \mu \mathrm{l}$ of ubiquitination assay buffer, was incubated with $5 \mathrm{nM}$ E1 activating enzyme provided by the E3Lite Customizable Ubiquitin Ligase kit, 100 nM E2 conjugating enzyme Ube2g2, $200 \mu \mathrm{M}$ ATP, 6 mM human recombinant ubiquitin, $1.5 \mu \mathrm{M}$ human recombinant E3 ligases Trc8/RNF-139 (Abnova) or gp78/AMFR (Abnova). AA, DHA or EPA were added at different concentrations. Samples were maintained at $37^{\circ} \mathrm{C}$ for $30 \mathrm{~min}$; the quantification of ubiquitinated HMGCoAR was performed as reported above. This assay was considered an index of the activity of Trc8 and gp78 E3 ligases, respectively.

\section{Lipid composition analysis}

Lipids were extracted according to [70] with three different chloroform/methanol mixtures (1:1, 1:2 and 2:1, v/v) and partitioned with water and with the theoretical upper phase (chloroform/methanol/water, 47:48:1, v/v). The organic phase was dried and then suspended in chloroform/ methanol $(2: 1, \mathrm{v} / \mathrm{v})$ for the analysis of total fatty acid and cholesterol contents. Each solvent contained $50 \mu \mathrm{M}$ 2,6bis(1,1-dimethylethyl)-4-methylphenol (BHT). 
Total fatty acids were determined as methyl esters by gas chromatography. The methyl esters were obtained by reaction with $3.33 \%(\mathrm{w} / \mathrm{v})$ sodium methoxide in methanol and injected into an Agilent Technologies (6850 series II) gas chromatograph equipped with a flame ionization detector and a capillary column (AT Silar) (length $30 \mathrm{~m}$, film thickness $0.25 \mu \mathrm{m}$ ). The carrier gas was helium, the injector temperature was $250^{\circ} \mathrm{C}$, the detector temperature was $275^{\circ}$ $\mathrm{C}$, the oven temperature was set at $50^{\circ} \mathrm{C}$ for $20 \mathrm{~min}$ and

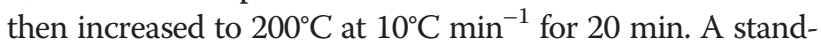
ard mixture containing all fatty acid methyl esters (Sigma) was injected for calibration, and heptadecanoic acid methyl ester (Sigma) was used as internal standard.

The cholesterol analysis was achieved by highpressure liquid chromatography HPLC (Jasco, Tokyo, Japan) equipped with ELSD detector (Sedere, Alfortville Cedex, France) and silica normal-phase LiChrospher Si 60 column (LiChroCART 250-4; Merck, Darmstadt, Germany). The cholesterol amount was related to the cell protein content.

\section{Isolation of Detergent Resistant Membranes (DRMs)}

The extraction of DRMs was performed as reported previously [51]. This is a common biochemical method to analyze the domain organization of membranes. Although detergent treatment disrupts most lipid-lipid interactions, a minor fraction of cell membranes is preserved and can be isolated as DRMs. DRMs represent no-native "lipid rafts" but they are a useful tool to study changes in composition related to biochemical, physiological or pathological raft associated events [71].

Cells were harvested by scraping in PBS containing $0.4 \mathrm{mM} \mathrm{Na}_{3} \mathrm{VO}_{4}$, then centrifuged at $1,300 \times \mathrm{g}$ for 2 min, suspended in $1.4 \mathrm{ml}$ lysis buffer (1\% Triton X100, $10 \mathrm{mM}$ Tris buffer, pH 7.5, $150 \mathrm{mM} \mathrm{NaCl}, 5 \mathrm{mM}$ EDTA, $1 \mathrm{mM} \mathrm{Na} \mathrm{VO}_{4}, 1 \mathrm{mM}$ PMSF, $75 \mathrm{mU} / \mathrm{ml}$ aprotinin), maintained in ice for $20 \mathrm{~min}$, and finally treated with Dounce homogenizer (10 strokes, tight). The DRMs were purified on sucrose gradient as previously described [35]. After centrifugation 11 fractions were collected; to confirm the purity of DRMs, the content of cholesterol, phospholipids, gangliosides, clathrin heavy chain and flotillin-1 was determined in each fraction by TLC and Western blot (data not shown). DRMs protein content, fatty acid composition and cholesterol content were analyzed as described above.

\section{Flow cytometry analysis}

Cells were washed twice with PBS, rinsed with $1 \mathrm{ml}$ of $0.25 \%(\mathrm{w} / \mathrm{v})$ PBS-BSA and centrifuged at 10,000 $\times \mathrm{g}$ for $5 \mathrm{~min}$. The pelleted cells were incubated for $45 \mathrm{~min}$ at $4^{\circ} \mathrm{C}$ with the anti-Pgp, anti-MRP1, anti-BCRP or anticalreticulin antibodies, then washed and incubated with a secondary FITC-conjugated antibody for $30 \mathrm{~min}$ at $4^{\circ} \mathrm{C}$ in the dark. After fixation in paraformaldehyde $2 \% \mathrm{v} / \mathrm{v}$, cells were re-suspended in $0.5 \mathrm{ml}$ PBS-BSA and analyzed using a FACS-Calibur system. For each analysis 100,000 events were collected. The percentage of viable (propidium iodide-negative) fluorescent cells was calculated by the Cell Quest software. Control experiments included incubation with non immune isotypic antibodies followed by the secondary antibody.

\section{Intracellular doxorubicin accumulation}

Intracellular doxorubicin content was detected with a fluorimetric assay as reported [41]. Cells were incubated for $24 \mathrm{~h}$ in medium containing $5 \mu \mathrm{M}$ doxorubicin, washed twice with PBS, detached with trypsin/EDTA, centrifuged for $30 \mathrm{~s}$ at $13,000 \times \mathrm{g}$, re-suspended in $1 \mathrm{ml}$ of a 1:1 mixture of ethanol/0.3 N HCl and sonicated. The protein content of the cell lysates was measured and the amount of intracellular doxorubicin was detected using a PerkinElmer LS-5 spectrofluorimeter (PerkinElmer). Excitation and emission wavelengths were 475 and $553 \mathrm{~nm}$, respectively. A blank was prepared in the absence of cells in each set of experiments and its fluorescence was subtracted from the one measured in each sample. The results were expressed as nmol doxorubicin/mg cell proteins according to a previously prepared calibration curve.

\section{Dendritic cell (DC) generation and in vitro phagocytosis assay}

The generation of DCs and their phagocytosis of colon cancer cells were performed as described earlier [26]. DCs were generated from peripheral blood samples obtained from healthy donors kindly provided by the local Blood Bank (Fondazione Strumia, Torino, Italy). Cells were harvested on day 6 and confirmed as immature DCs by morphology and immunophenotype (data not shown). HT29 and HT29-dx cells were green-stained with PKH2FITC (Sigma), washed twice and incubated with DCs at a ratio of $1: 1$ for $18 \mathrm{~h}$ at $37^{\circ} \mathrm{C}$. Co-cultures were then stained for 20 min at $4^{\circ} \mathrm{C}$ with APC-conjugated HLA-DR antibody (Miltenyi Biotec, Tetrow, Germany) to mark DCs. Twocolor flow cytometry was performed with FACS-Calibur system and CellQuest software. At least 10,000 events were accumulated specifically backgating on DC morphology (region 1: FSC versus SSC). Tumor cell phagocytosis was assessed as the percentage of double-stained (FITC plus APC) cells. Tumor cells do not express significant amounts of HLA-DR, and they were excluded from region 1 by their morphology. In each set of experiments, a phagocytosis assay was performed by co-incubating DCs and tumor cells at $4^{\circ} \mathrm{C}$, instead of $37^{\circ} \mathrm{C}$, and the percentage of double-stained cells obtained after the incubation at $4^{\circ} \mathrm{C}$ was subtracted from values observed at $37^{\circ} \mathrm{C}$. The phagocytosis rate was expressed as "phagocytic index", calculated as reported in [42]. 


\section{Statistical analysis}

Data are reported as mean \pm SD of at least three independent experiments. Results were checked for normal distribution and analyzed by a one-way analysis of variance (ANOVA) followed by Dunnet's $\mathrm{t}$ test. $\mathrm{p}<0.05$ was considered significant.

\section{Additional files}

Additional file 1: Effects of $\omega 3$ PUFAs on apoptosis and necrotic/ immunogenic death of colon cancer cells. HT29 and HT29-dx cells were incubated for $24 \mathrm{~h}$ in the absence (CTRL) or presence of $50 \mu \mathrm{M}$ arachidonic acid (AA), docosahexaenoic acid (DHA), eicosapentaenoic acid (EPA). Cycloheximide ( $4 \mu \mathrm{M}$ for $24 \mathrm{~h}, \mathrm{CHX}$ ) was chosen as positive control of cytotoxicity in both chemosensitive and chemoresistant cells: doxorubicin ( $5 \mu \mathrm{M}$ for $24 \mathrm{~h}, \mathrm{DOX}$ ) was chosen as positive control of cytotoxicity in chemosensitive cells. A. Annexin V staining. The percentage of cells positive for surface annexin $V$, taken as index of apoptosis, was measured in duplicate by flow cytometry. Data are presented as means \pm SD $(n=3)$. Versus respective CTRL: ${ }^{*} p<0.001$; DOX in HT29-dx versus DOX in HT29: ${ }^{\circ} p<0.001$. B. Western blot analysis of extracellular HMGB1, taken as index of necrotic/immunogenic death. Red Ponceau staining was used to check the equal loading of proteins. The figure is representative of two experiments with similar results. The band density ratio between HMGB1 and the Red Ponceau-positive bands was expressed as arbitrary units. Versus CTRL HT29: * $p<0.002$

\section{Additional file 2: Effects of $\omega 3$ PUFAs on HMGCoAS transcription} and SREBPs nuclear translocation in colon cancer cells. HT29 and HT29-dx cells were incubated for $24 \mathrm{~h}$ in the absence (CTRL) or presence of $50 \mu \mathrm{M}$ arachidonic acid (AA), docosahexaenoic acid (DHA), eicosapentaenoic acid (EPA). A. Total RNA was extracted, reverse-transcribed and subjected to qRT-PCR for HMGCOAS gene. Measurements were performed in triplicate and data are presented as means $\pm S D(n=3)$. Versus CTRL HT29: * $p<0.05$. B. Western blot detection of SREBP2 and SREBP1, performed on nuclear extracts. Proliferating cell nuclear antigen (PCNA) expression was used as a control of equal loading of nuclear proteins. The figure is representative of three experiments with similar results. The band density ratio between each protein and PCNA was expressed as arbitrary units. Versus CTRL HT29: ${ }^{*} p<0.02$.

Additional file 3: Effects of $\omega 3$ PUFAs on Pgp, MRP1 and BCRP expression in colon cancer cells. HT29 and HT29-dx cells were incubated for $48 \mathrm{~h}$ in the absence (CTRL) or presence of $50 \mu \mathrm{M}$ arachidonic acid (AA), docosahexaenoic acid (DHA), eicosapentaenoic acid (EPA). The expression of Pgp, MRP1 and BCRP was measured on whole cell lysates by Western blotting. Tubulin expression was used as a control of equal protein loading. The figure is representative of three experiments with similar results. The band density ratio between each protein and tubulin was expressed as arbitrary units. Versus CTRL HT29: ${ }^{*} p<0.02$

\section{Additional file 4: $\omega 3$ PUFAs restore the pro-immunogenic death} induced by doxorubicin in chemoresistant colon cancer cells. HT29 and HT29-dx cells were incubated for $48 \mathrm{~h}$ in the absence (CTRL) or presence of $50 \mu \mathrm{M}$ arachidonic acid (AA), docosahexaenoic acid (DHA), eicosapentaenoic acid (EPA). $5 \mu \mathrm{M}$ doxorubicin (DOX) was added for $24 \mathrm{~h}$, alone or during the last $24 \mathrm{~h}$ of incubation with fatty acids. Cycloheximide ( $4 \mu \mathrm{M}$ for $24 \mathrm{~h}, \mathrm{CHX}$ ) was chosen as positive control of cytotoxicity in both chemosensitive and chemoresistant cells. A. The release of extracellular ATP was measured in triplicate by a chemiluminscent assay. Data are presented as means $\pm S D(n=4)$. Versus respective $C T R L$ : ${ }^{*} p<0.02$; versus DOX alone: ${ }^{\circ} p<0.01$. D. Western blot analysis of extracellular HMGB1, taken as index of necrosis and immunogenic death. Red Ponceau staining was used to check the equal loading of protein. The figure is representative of two experiments with similar results. The band density ratio between HMGB1 and the Red Ponceau-positive bands was expressed as arbitrary units. Versus CTRL HT29: * $p<0.002$; versus CTRL H29-dx: ${ }^{\circ} p<0.002$.
Additional file 5: Chemo-immunosensitizing effects of w3PUFAs in chemoresistant colon cancer cells. A. MDR cells such as HT29-dx have deficient activity of the $\operatorname{Trc} 8 \mathrm{E} 3$ ubiquitin ligase, higher expression and activity of 3-hydroxy-3-methylglutaryl-coenzyme A reductase, higher synthesis of cholesterol and higher levels of cholesterol in plasma-membrane. This situation favours the activity of ATP binding cassette transporters such as P-glycoprotein and limits the intracellular accumulation of specific chemotherapeutic drugs like doxorubicin, which is not able to induce direct cytotoxicity on tumor cell and to translocate calreticulin on cell surface, the first step to induce cell phagocytosis by dendritic cells. B. Docosahexaenoic acid and eicosapentaenoic acid restore the Trc8-mediated ubiquitnation of 3-hydroxy-3-methylglutaryl-coenzyme A reductase and its proteasomal degradation, lower the cholesterol synthesis and the amount of cholesterol in plasma-membrane and detergent resistant membranes. Moreover they are well incorporated in whole cell membrane and detergent resistant membranes, where they alter the physicochemical properties of the lipid environment and reduce the amount of P-glycoprotein. As a result, doxorubicin is more accumulated in MDR cells, exerts cytotoxic effects and promotes the surface translocation of calreticulin, followed by the dendritic cells-mediated phagocytosis. MDR: multidrug resistance; HMGCOAR: 3-hydroxy-3-methylglutaryl-coenzyme A reductase; Uq: ubiquitin; SREBP2: sterol regulatory element binding protein-2, Pgp: P-glycoprotein; CRT: calreticulin; d: doxorubicin; DHA: docosahexaenoic acid; EPA: eicosapentaenoic acid.

\section{Abbreviations}

w3/w6PUFAs: Omega 3/omega 6 polyunsaturated fatty acids; DHA: Docosahexaenoic acid; EPA: Eicosapentaenoic acid; HDL: High density lipoprotein; LDL: Low density lipoprotein; HMGCoAR: 3-hydroxy-3methylglutaryl-coenzyme a reductase; SREBP: Sterol regulatory element binding protein; HMGCOAS: 3-hydroxy-3-methylglutaryl-coenzyme a synthase; MDR: Multidrug resistance; ABC: ATP binding cassette; Pgp: Pglycoprotein; MRP: Multidrug resistance related protein; BCRP: Breast cancer resistance protein; DRMs: Detergent resistant membranes; AA: Arachidonic acid; DPA: Docosapentaenoic acid; FBS: Fetal bovine serum; BSA: Bovine serum albumin; PBS: Phosphate-buffered saline; TLC: Thin layer chromatography; FITC: Fluorescein isothiocyanate; HMGB1: High-mobility group 1 box; PMSF: 4-(2-aminoethyl)benzenesulfonyl fluoride; DTT: Dithiothreitol; PCNA: Proliferating cell nuclear antigen; RLU: Relative luminescence unit; HPLC: High-pressure liquid chromatography; DC: Dendritic cell; ER: Endoplasmic reticulum; ERAD: ER-associated degradation; HIF-1a: Hypoxia inducible factor-1a; SFA: Saturated fatty acids; MUFA: Mono-unsaturated fatty acids.

\section{Competing interests}

The authors declare that they have no competing interests.

\section{Authors' contributions}

GG and PAC performed the cell viability assays, immunoassays and lipid analysis experiments; IC carried out the metabolic radiolabelling assays; GM participated in the lipid analysis experiments; JK, BC and EG carried out the flow cytometric analysis, the phagocytosis assays and the experiments with chemotherapeutic drugs; DG participated in the design of the study and analyzed the data; AMR and CR conceived of the study, analyzed the data and wrote the manuscript. All authors read and approved the final manuscript.

\section{Authors' information}

JK is the recipient of a "Mario e Valeria Rindi" fellowship from Italian Foundation for Cancer Research (FIRC).

\section{Acknowledgements}

We thank Costanzo Costamagna, Dept. of Oncology, University of Torino, for the technical assistance.

This work was supported by: Italian Association of Cancer Research (grant: MFAG 11475 to (R), Italian Ministry of University and Research - Future in Research Program 2012 (grant: RBFR12SOQ1 to CR), Italian Space Agency (grant I/012/11/0 to AMR). The funders had no role in study design, data collection and analysis, decision to publish, or preparation of the manuscript. 


\section{Author details}

1 Department of Oncology, University of Torino, via Santena 5/bis, 10126 Torino, Italy. ${ }^{2}$ Department of Pharmacological and Biomolecular Sciences, University of Milano, via Trentacoste 2, 20134 Milan, Italy. ${ }^{3}$ Center for Experimental Research and Medical Studies, University of Torino, via Santena 5/bis, 10126 Torino, Italy.

Received: 13 August 2013 Accepted: 11 November 2013 Published: 13 November 2013

\section{References}

1. Chang CL, Deckelbaum RJ: Omega-3 fatty acids: mechanisms underlying 'protective effects' in atherosclerosis. Curr Opin Lipidol 2013, 24:345-350.

2. Maskrey BH, Megson IL, Rossi AG, Whitfield PD: Emerging importance of omega-3 fatty acids in the innate immune response: molecular mechanisms and lipidomic strategies for their analysis. Mol Nutr Food Res 2013, 57:1390-1400.

3. Laviano A, Rianda S, Molfino A, Rossi Fanelli F: Omega-3 fatty acids in cancer. Curr Opin Clin Nutr Metab Care 2013, 16:156-161.

4. Dewell A, Marvasti FF, Harris WS, Tsao P, Gardner CD: Low- and high-dose plant and marine ( $n-3)$ fatty acids do not affect plasma inflammatory markers in adults with metabolic syndrome. J Nutr 2011, 141:2166-2171.

5. Jeckel KM, Veeramachaneni DN, Chicco AJ, Chapman PL, Mulligan CM, Hegarty JR, Pagliassotti MJ, Ferguson LA, Bouma GJ, Frye MA: Docosahexaenoic acid supplementation does not improve western diet-induced cardiomyopathy in rats. PLoS One 2012, 7:e51994.

6. Galvao TF, Khairallah RJ, Dabkowski ER, Brown BH, Hecker PA, O'Connell KA O'Shea KM, Sabbah HN, Rastogi S, Daneault C, Des Rosiers C, Stanley WC: Marine $\mathrm{n} 3$ polyunsaturated fatty acids enhance resistance to mitochondrial permeability transition in heart failure but do not improve survival. Am J Physiol Heart Circ Physiol 2013, 304:H12-H21.

7. Brasky TM, Darke AK, Song X, Tangen CM, Goodman PJ, Thompson IM, Meyskens FL Jr, Goodman GE, Minasian LM, Parnes HL, Klein EA, Kristal AR: Plasma phospholipid fatty acids and prostate cancer risk in the SELECT trial. J Natl Cancer Inst 2013, 105:1132-1141.

8. Chua ME, Sio MC, Sorongon MC, Morales ML Jr: The relevance of serum levels of long chain omega-3 polyunsaturated fatty acids and prostate cancer risk: a meta-analysis. Can Urol Assoc J 2013, 7:E333-E343.

9. Sorongon-Legaspi MK, Chua M, Sio MC, Morales M Jr: Blood level omega-3 fatty acids as risk determinant molecular biomarker for prostate cancer. Prostate Cancer 2013, 2013:e875615.

10. Alexander W: Prostate cancer risk and omega-3 fatty acid intake from fish oil. PT 2013, 38:561-564

11. Geelen A, Schouten JM, Kamphuis C, Stam BE, Burema J, Renkema JM, Bakker EJ, van't Veer P, Kampman E: Fish consumption, n-3 fatty acids, and colorectal cancer: a meta-analysis of prospective cohort studies. Am J Epidemiol 2007, 166:1116-1125

12. Fini L, Piazzi G, Ceccarelli C, Daoud Y, Belluzzi A, Munarini A, Graziani G, Fogliano V, Selgrad M, Garcia M, Gasbarrini A, Genta RM, Boland CR, Ricciardiello L: Highly purified eicosapentaenoic acid as free fatty acids strongly suppresses polyps in Apc(Min/+) mice. Clin Cancer Res 2010, 16:5703-5711

13. Courtney ED, Matthews S, Finlayson C, Di Pierro D, Belluzzi A, Roda E, Kang JY, Leicester RJ: Eicosapentaenoic acid (EPA) reduces crypt cell proliferation and increases apoptosis in normal colonic mucosa in subjects with a history of colorectal adenomas. Int J Colorectal Dis 2007, 22:765-776.

14. Hofmanová J, Vaculová A, Kozubík A: Polyunsaturated fatty acids sensitize human colon adenocarcinoma HT-29 cells to death receptor-mediated apoptosis. Cancer Lett 2005, 218:33-41.

15. Pan J, Keffer J, Emami A, Ma X, Lan R, Goldman R, Chung FL: Acrolein-derived DNA adduct formation in human colon cancer cells: its role in apoptosis induction by docosahexaenoic acid. Chem Res Toxicol 2009, 22:798-806.

16. Habermann N, Lund EK, Pool-Zobel BL, Glei M: Modulation of gene expression in eicosapentaenoic acid and docosahexaenoic acid treated human colon adenoma cells. Genes Nutr 2009, 4:73-76.

17. Sheril A, Jeyakumar SM, Jayashree T, Giridharan NV, Vajreswari A: Impact of feeding polyunsaturated fatty acids on cholesterol metabolism of dyslipidemic obese rats of WNIN/GR-Ob strain. Atherosclerosis 2009, 204:136-140.
18. Balk EM, Lichtenstein AH, Chung M, Kupelnick B, Chew P, Lau J: Effects of omega-3 fatty acids on serum markers of cardiovascular disease risk: a systematic review. Atherosclerosis 2006, 189:19-30.

19. Jacobson TA, Glickstein SB, Rowe JD, Soni PN: Effects of eicosapentaenoic acid and docosahexaenoic acid on low-density lipoprotein cholesterol and other lipids: a review. J Clin Lipido/ 2012, 6:5-18.

20. Martini C, Pallottini V, De Marinis E, Marino M, Cavallini G, Donati A, Straniero S, Trentalance A: Omega-3 as well as caloric restriction prevent the age-related modifications of cholesterol metabolism. Mech Ageing Dev 2008, 129:722-727.

21. Duncan RE, El-Sohemy A, Archer MC: Dietary factors and the regulation of 3-hydroxy-3-methylglutaryl coenzyme a Reductase: implications for breast cancer and development. Mol Nutr Food Res 2005, 49:93-100.

22. Murthy S, Albright E, Mathur SN, Field FJ: Modification of Caco-2 cell membrane fatty acid composition by eicosapentaenoic acid and palmitic acid: effect on cholesterol metabolism. J Lipid Res 1988, 29:773-780.

23. Jakobsen CH, Størvold GL, Bremseth H, Follestad T, Sand K, Mack M, Olsen KS, Lundemo AG, Iversen JG, Krokan HE, Schønberg SA: DHA induces ER stress and growth arrest in human colon cancer cells: associations with cholesterol and calcium homeostasis. J Lipid Res 2008, 49:2089-2100.

24. Størvold GL, Fleten KG, Olsen CG, Follestad T, Krokan HE, Schønberg SA: Docosahexaenoic acid activates some SREBP-2 targets independent of cholesterol and ER stress in SW620 colon cancer cells. Lipids 2009, 44:673-683.

25. Kopecka J, Campia I, Olivero P, Pescarmona G, Ghigo D, Bosia A, Riganti C: A LDL-masked liposomal-doxorubicin reverses drug resistance in human cancer cells. J Control Release 2011, 149:196-205.

26. Riganti C, Castella B, Kopecka J, Campia I, Coscia M, Pescarmona G, Bosia A, Ghigo D, Massaia M: Zoledronic acid restores doxorubicin chemosensitivity and immunogenic cell death in multidrug-resistant human cancer cells. PLoS One 2013, 8:e60975.

27. Gottesman MM, Fojo T, Bates SE: Multidrug resistance in cancer: role of ATP-dependent transporters. Nat Rev Cancer 2002, 2:48-58.

28. Eckford PDW, Sharom FJ: Interaction of the P-glycoprotein multidrug efflux pump with cholesterol: effects on ATPase activity, drug binding and transport. Biochemistry 2008, 47:13686-13698.

29. Bacso Z, Nagy H, Goda K, Bene L, Fenyvesi F, Matkó J, Szabó G: Raft and cytoskeleton associations of an $A B C$ transporter: P-glycoprotein. Cytometry A 2004, 61:105-116.

30. Storch $\mathrm{CH}$, Ehehalt $\mathrm{R}$, Haefeli WE, Weiss J: Localization of the human breast cancer resistance protein (BCRP/ABCG2) in lipid rafts/caveolae and modulation of its activity by cholesterol in vitro. J Pharmacol Exp Ther 2007, 323:257-264

31. Klappe K, Hinrichs JW, Kroesen BJ, Sietsma H, Kok JW: MRP1 and glucosylceramide are co-ordinately over expressed and enriched in rafts during multidrug resistance acquisition in colon cancer cells. Int J Cancer 2004, 110:511-522

32. Lavie $Y$, Liscovitch $M$ : Changes in lipid and protein constituents of rafts and caveolae in multidrug resistant cancer cells and their functional consequences. Glycoconj J 2000, 17:253-259.

33. Corsetto PA, Montorfano G, Zava S, Jovenitti IE, Cremona A, Berra B, Rizzo AM: Effects of $n-3$ PUFAs on breast cancer cells through their incorporation in plasma membrane. Lipids Health Dis 2011, 10:e73.

34. Chapkin RS, McMurray DN, Davidson LA, Patil BS, Fan YY, Lupton JR: Bioactive dietary long-chain fatty acids: emerging mechanisms of action. Br J Nutr 2008, 100:1152-1157.

35. Corsetto PA, Cremona A, Montorfano G, Jovenitti IE, Orsini F, Arosio P, Rizzo AM: Chemical-physical changes in cell membrane microdomains of breast cancer cells after omega-3 PUFA incorporation. Cell Biochem Biophys 2012, 64:45-59.

36. Shaikh SR: Biophysical and biochemical mechanisms by which dietary $\mathrm{N}-3$ polyunsaturated fatty acids from fish oil disrupt membrane lipid rafts. J Nutr Biochem 2012, 23:101-105.

37. Orsini F, Cremona A, Arosio P, Corsetto PA, Montorfano G, Lascialfari A Rizzo AM: Atomic force microscopy imaging of lipid rafts of human breast cancer cells. Biochim Biophys Acta 1818, 2012:2943-2949.

38. Edwards PA, Show-Fung L, Fogelman AM: The effect of glucagon on the synthesis and degradation of 3-hydroxy-3-methylglutaryl coenzyme A reductase. J Lipid Res 1986, 27:398-403.

39. Jo Y, Lee PCW, Sguigna PV, DeBose-Boyd RA: Sterol-induced degradation of HMG CoA reductase depends on interplay of two Insigs and two ubiquitin ligases, gp78 and Trc8. Proc Natl Acad Sci 2011, 108:20503-20508. 
40. Miao H, Jiang W, Ge L, Li B, Song B: Tetra-glutamic acid residues adjacent to Lys 248 in HMG-CoA reductase are critical for the ubiquitination mediated by gp78 and UBE2G2. Acta Biochim Biophys Sin (Shanghai) 2010, 42:303-310.

41. Riganti C, Miraglia E, Viarisio D, Costamagna C, Pescarmona G, Ghigo D, Bosia A: Nitric oxide reverts the resistance to doxorubicin in human colon cancer cells by inhibiting the drug efflux. Cancer Res 2005, 65:516-525.

42. Obeid M, Tesniere A, Ghiringhelli F, Fimia GM, Apetoh L, Perfettini JL, Castedo M, Mignot G, Panaretakis T, Casares N, Métivier D, Larochette N, van Endert P, Ciccosanti F, Piacentini M, Zitvogel L, Kroemer G: Calreticulin exposure dictates the immunogenicity of cancer cell death. Nat Med 2007, 13:54-61.

43. Zappasodi R, Pupa SM, Ghedini GC, Bongarzone I, Magni M, Cabras AD, Colombo MP, Carlo-Stella C, Gianni AM, Di Nicola A: Improved clinical outcome in indolent B-cell lymphoma patients vaccinated with autologous tumor cells experiencing immunogenic death. Cancer Res 2010, 70:9062-9072

44. Luo F, Paranjpe PV, Guo A, Rubin E, Sinko P: Intestinal transport of irinotecan in Caco-2 cells and MDCK II cells overexpressing efflux transporters Pgp, cMOAT and MRP1. Drug Metab Dispos 2002, 30:763-770.

45. Calviello G, Di Nicuolo F, Serini S, Piccioni E, Boninsegna A, Maggiano N, Ramelletti FO, Palozza P: Docosahexaenoic acid enhances the susceptibility of human colorectal cancer cells to 5-fluorouracil. Cancer Chemother Pharmacol 2005, 55:12-22.

46. Habermann N, Christian B, Luckas B, Pool-Zobel BL, Lund EK, Glei M: Effects of fatty acids on metabolism and cell growth of human colon cell lines of different transformation state. Biofactors 2009, 35:460-467.

47. Gossett RE, Frolov AA, Roths JB, Behnke WD, Kier AB, Schroeder F: Acyl-CoA binding proteins: multiplicity and function. Lipids 1996, 31:895-918.

48. Pallottini V, Guantario B, Martini C, Totta P, Filippi I, Carraro F, Trentalance A: Regulation of HMG-CoA reductase expression by hypoxia. J Cell Biochem 2008, 104:701-709.

49. Chen B, Mariano J, Tsai YC, Chan AH, Cohen M, Weissman AM: The activity of a human endoplasmic reticulum associated degradation E3, gp78, requires its Cue domain, RING finger, and an E2-binding site. Proc Natl Acad Sci 2006, 103:341-346.

50. Calviello G, Resci F, Serini S, Piccioni E, Toesca A, Boninsegna A, Monego G, Ranelletti FO, Palozza P: Docosahexaenoic acid induces proteasomedependent degradation of beta-catenin, down-regulation of survivin and apoptosis in human colorectal cancer cells not expressing COX-2. Carcinogenesis 2007, 28:1202-1209.

51. Simons K, Toomre D: Lipid rafts and signal transduction. Nat Rev Mol Cell Biol 2000, 1:31-39.

52. Lingwood D, Simons K: Lipid rafts as a membrane-organizing principle. Science 2010, 327:46-50.

53. Lavie Y, Fiucci G, Liscovitch M: Up-regulation of caveolae and caveolar constituents in multidrug-resistant cancer cells. J Biol Chem 1998, 273:32380-32383.

54. Meyer dos Santos S, Weber CC, Franke C, Müller WE, Eckert GP: Cholesterol: coupling between membrane microenvironment and $A B C$ transporter activity. Biochem Biophys Res Commun 2007, 354:216-221.

55. Shaikh SR, Rockett BD, Salameh M, Carraway K: Docosahexaenoic acid modifies the clustering and size of lipid rafts and the lateral organization and surface expression of MHC class I of EL4 cells. J Nutr 2009, 139:1632-1639.

56. Williams JA, Batten SE, Harris M, Rockett BD, Shaikh SR, Stillwell W, Wassall SR: Docosahexaenoic and eicosapentaenoic acids segregate differently between raft and nonraft domains. Biophys J 2012, 103:228-237.

57. Rockett BD, Teague H, Harris M, Melton M, Williams J, Wassall SR, Shaikh SR: Fish oil increases raft size and membrane order of $B$ cells accompanied by differential effects on function. J Lipid Res 2012, 53:674-685.

58. Riganti C, Voena C, Kopecka J, Corsetto PA, Montorfano G, Enrico E, Costamagna C, Rizzo AM, Ghigo D, Bosia A: Liposome-encapsulated doxorubicin reverses drug resistance by inhibiting P-glycoprotein in human cancer cells. Mol Pharm 2011, 8:683-700.

59. Kuan CY, Walker TH, Luo PG, Chen CF: Long-chain polyunsaturated fatty acids promote paclitaxel cytotoxicity via inhibition of the MDR1 gene in the human colon cancer Caco-2 cell line. J Am Coll Nutr 2011, 30:65-273.

60. Peng RQ, Chen YB, Ding Y, Zhang R, Zhang $X$, Yu XJ, Zhou ZW, Zeng YX, Zhang XS: Expression of calreticulin is associated with infiltration of T-cells in stage IIIB colon cancer. World J Gastroenterol 2010, 16:2428-2434.
61. Correale P, Tagliaferri P, Fioravanti A, Del Vecchio MT, Remondo C, Montagnani F, Rotundo MS, Ginanneschi C, Martellucci I, Francini E, Cusi MG, Tassone P, Francini G: Immunity feedback and clinical outcome in colon cancer patients undergoing chemoimmunotherapy with gemcitabine + FOLFOX followed by subcutaneous GranulocyteMacrophage Colony-stimulating Factor and Aldesleukin (GOLFIG-1Trial). Clin Cancer Res 2008, 14:4192-4199.

62. Medina-Echeverz J, Fioravanti J, Zabala M, Ardaiz N, Prieto J, Berraondo P: Successful colon cancer eradication after chemoimmunotherapy is associated with profound phenotypic change of intratumoral myeloid cells. J Immunol 2011, 186:807-815.

63. Granci V, Cai F, Lecumberri E, Clerc A, Dupertuis YM, Pichard C: Colon cancer cell chemosensitisation by fish oil emulsion involves apoptotic mitochondria pathway. Br J Nutr 2013, 109:1188-1195.

64. Xue H, Le Roy S, Sawyer MB, Field CJ, Dieleman LA, Baracos VE: Single and combined supplementation of glutamine and $n-3$ polyunsaturated fatty acids on host tolerance and tumour response to 7-ethyl-10-[4-(1-piperidino)-1piperidino]carbonyloxy-camptothecin (CPT-11)/5-fluorouracil chemotherapy in rats bearing Ward colon tumour. Br J Nutr 2009, 102:434-442

65. Bougnoux P, Hajjaji N, Ferrasson MN, Giraudeau B, Couet C, Le Floch O: Improving outcome of chemotherapy of metastatic breast cancer by docosahexaenoic acid: a phase II trial. Br J Cancer 2009, 101:1978-1985.

66. Murphy RA, Mourtzakis M, Chu QS, Baracos VE, Reiman T, Mazurak VC: Supplementation with fish oil increases first-line chemotherapy efficacy in patients with advanced nonsmall cell lung cancer. Cancer 2011 117:3774-3780.

67. Das UN, Madhavi N: Effect of polyunsaturated fatty acids on drug-sensitive and resistant tumor cells in vitro. Lipids Health Dis 2011, 10:e159.

68. Riganti C, Rolando B, Kopecka J, Campia I, Chegaev K, Lazzarato L, Federico A, Fruttero R, Ghigo D: Mitochondrial-targeting nitrooxy-doxorubicin: a new approach to overcome drug resistance. Mol Pharm 2013, 10:161-174

69. Campia I, Gazzano E, Pescarmona G, Ghigo D, Bosia A, Riganti C: Digoxin and ouabain increase the synthesis of cholesterol in human liver cells. Cell Mol Life Sci 2009, 66:1580-1594.

70. Folch J, Lees M, Stanley GHS: A simple method for the isolation and purification of total lipids from animal tissues. J Biol Chem 1957, 226:497-509.

71. Lingwood D, Simons K: Detergent resistance as a tool in membrane research. Nat Protoc 2007, 2:2159-2165.

doi:10.1186/1476-4598-12-137

Cite this article as: Gelsomino et al:: Omega 3 fatty acids chemosensitize multidrug resistant colon cancer cells by down-regulating cholesterol synthesis and altering detergent resistant membranes composition. Molecular Cancer 2013 12:137.

\section{Submit your next manuscript to BioMed Central and take full advantage of:}

- Convenient online submission

- Thorough peer review

- No space constraints or color figure charges

- Immediate publication on acceptance

- Inclusion in PubMed, CAS, Scopus and Google Scholar

- Research which is freely available for redistribution 